\title{
Re-evaluating the role of nucleosomal bivalency in early development
}

\author{
Rohan N. Shah"1,2,*, Adrian T. Grzybowski2,, Jimmy Elias ${ }^{2, *}$, Zhonglei Chen ${ }^{3,4}$, Takamitsu \\ Hattori5 $^{5,6}$, Carolin C. Lechner ${ }^{7,8}$, Peter W. Lewis ${ }^{9}$, Shohei Koide ${ }^{5,6,10}$, Beat Fierz ${ }^{7}$,
}

Alexander J. Ruthenburg 2,10

${ }^{1}$ Pritzker School of Medicine, The University of Chicago, Chicago, Illinois, 60637, USA.

${ }^{2}$ Department of Molecular Genetics and Cell Biology, The University of Chicago, Chicago, Illinois, 60637, USA.

${ }^{3}$ Department of Chemistry, The University of Chicago, Chicago, Illinois, 60637 USA.

${ }^{4}$ Present address: Lyvgen Biopharma, Shanghai 201203, P.R. China.

${ }^{5}$ Laura and Isaac Perlmutter Cancer Center, New York University Langone Medical Center, New York 10016, USA.

${ }^{6}$ Department of Biochemistry and Molecular Pharmacology, New York University School of Medicine, New York 10016, USA.

${ }^{7}$ Laboratory of Biophysical Chemistry of Macromolecules, Institute of Chemical Sciences and Engineering, École Polytechnique Fédérale de Lausanne (EPFL), 1015 Lausanne, Switzerland.

${ }^{8}$ Present address: Bachem AG, 4416 Bubendorf, Switzerland.

${ }^{9}$ Wisconsin Institute for Discovery and Department of Biomolecular Chemistry, School of Medicine and Public Health, University of Wisconsin, Madison, Wisconsin, USA.

${ }^{10}$ Department of Biochemistry and Molecular Biology, The University of Chicago, Chicago, Illinois, 60637, USA. *These authors contributed equally to this work.

Correspondence and requests for materials should be addressed to A.J.R. (email: aruthenburg@uchicago.edu). 


\section{Abstract}

2 Nucleosomes, composed of DNA and histone proteins, represent the fundamental repeating unit

3 of the eukaryotic genome ${ }^{1}$; posttranslational modifications of these histone proteins influence the

4 activity of the associated genomic regions to regulate cell identity ${ }^{2-4}$. Traditionally,

5 trimethylation of histone 3-lysine 4 (H3K4me3) is associated with transcriptional initiation ${ }^{5-10}$,

6 whereas trimethylation of H3K27 (H3K27me3) is considered transcriptionally repressive ${ }^{11-15}$.

7 The apparent juxtaposition of these opposing marks, termed "bivalent domains"16-18, was

8 proposed to specifically demarcate of small set transcriptionally-poised lineage-commitment

9 genes that resolve to one constituent modification through differentiation, thereby determining

10 transcriptional status ${ }^{19-22}$. Since then, many thousands of studies have canonized the bivalency

11 model as a chromatin hallmark of development in many cell types. However, these conclusions

12 are largely based on chromatin immunoprecipitations (ChIP) with significant methodological

13 problems hampering their interpretation. Absent direct quantitative measurements, it has been

14 difficult to evaluate the strength of the bivalency model. Here, we present reICeChIP, a

15 calibrated sequential ChIP method to quantitatively measure H3K4me3/H3K27me3 bivalency

16 genome-wide, addressing the limitations of prior measurements. With reICeChIP, we profile

17 bivalency through the differentiation paradigm that first established this model ${ }^{16,18}$ : from naïve

18 mouse embryonic stem cells (mESCs) into neuronal progenitor cells (NPCs). Our results cast

19 doubt on every aspect of the bivalency model; in this context, we find that bivalency is

20 widespread, does not resolve with differentiation, and is neither sensitive nor specific for

21 identifying poised developmental genes or gene expression status more broadly. Our findings

22 caution against interpreting bivalent domains as specific markers of developmentally poised

23 genes. 
In its original conception, the bivalency model posits that the combination of H3K4me3

25 and H3K27me3 represents a specific regulatory marker of developmentally staged genes.

26 Specifically, lineage commitment genes are thought to be held in a low-expression,

27 transcriptionally "poised” state by promoter nucleosomes bearing both H3K4me3 and

28 H3K27me3 ${ }^{16,18,21,22}$. Upon differentiation, the bivalent domain “resolves” into a monovalent

29 state, and the associated gene is either transcriptionally activated or terminally repressed if

30 H3K27me3 or H3K4me3 is lost, respectively ${ }^{16,18,21,22}$. The elegance of this instructive model

31 inspired a host of follow-on studies that have suggested that bivalency is important in

32 differentiation ${ }^{23-30}$, embryogenesis ${ }^{17,31-34}$, genome architecture ${ }^{22,35-38}$, and oncogenesis ${ }^{39-43}$.

In the absence of unambiguous biochemical or functional validation ${ }^{17,44,45}$, these studies

34 have largely relied upon ChIP, with the vast majority of studies defining loci with independent

35 ChIP enrichment for H3K4me3 and H3K27me3 as bivalent domains. However, this analysis

36 cannot distinguish whether the two modifications coexist or represent two distinctly marked

37 subpopulations of alleles or cells. Further, because different ChIPs are normalized separately,

38 they exist on separate relative scales and cannot be quantitatively compared without internal

39 calibration ${ }^{46-48}$. As such, it is impossible to quantify the extent of bivalency at a given locus or to

40 measure its changes through differentiation.

To address the first problem, several studies have used sequential ChIP ${ }^{16,29,49-51}$,

42 measuring coexistence by using the eluent of an IP against H3K4me3 as the substrate for an IP

43 against H3K27me3 (or vice versa). However, these experiments used antibodies of unknown

44 specificity $^{16,29,49-51}$, were uncalibrated, and were often undersampled ${ }^{50,52}$, precluding

45 quantification of the extent of modification. Moreover, many used relatively large chromatin

46 fragments in their pulldowns, making it difficult to determine whether modifications coexisted 
47 on one nucleosome or discretely marked neighbouring nucleosomes ${ }^{16,29,50,51}$. The limitations of

48 these sequential ChIP studies preclude accurate assessment of key properties of bivalency.

50 nucleosome internal standards are used to measure antibody specificity and as analytical

51 calibrants that enable computation of the histone modification density (HMD), or the proportion

52 of nucleosomes at a given locus with the modification of interest ${ }^{46-48}$. By identifying regions

53 with high H3K4me3 and H3K27me3, we indirectly identified many promoters with a nonzero

54 amount of bivalency, including those regulating developmental and metabolic genes ${ }^{46}$. However,

55 this analysis was limited; it was not sensitive for bivalency at less extensively modified loci, nor

56 could it quantify the extent of bivalency. Here, we directly quantify this nucleosomal mark

57 pattern by calibration of a modified sequential ChIP approach to critically evaluate the bivalency

58 model in the differentiation system in which the foundational observations were made.

\section{Measuring bivalency with reICeChIP}

61 To directly measure bivalency and evaluate its role in differentiation, we first attempted to

62 deploy our calibrants with published sequential ChIP methods. However, when evaluated with

63 internal standards, these methods ${ }^{16,29,49}$ displayed extremely low enrichment and variable

64 specificity (Extended Data Fig. 1a), with common elution methods either failing to release most

65 of the captured material ${ }^{51}$ or compromising the specificity of the second IP (Extended Data Fig.

66 1b-c). With such heavy losses, we became concerned that we would undersample and potentially

67 bias the measurement of bivalent nucleosomes. We sought a method of elution from the primary

68 IP that was both more efficient and would preserve nucleosome integrity for the second IP. To

69 that end, we modified a recombinant biotinylated Fab (304M3-B) specific for H3K4me3 ${ }^{53}$ with 
70 an intervening HRV 3C endoprotease cleavage site to enable quantitative elution by enzymatic

71 cleavage under mild conditions.

We then leveraged this reagent to develop reICeChIP (Fig. 1a). The first pulldown was

73 conducted with the cleavable $\alpha$-H3K4me3 Fab from native mononucleosomes ${ }^{46,54}$ spiked with

74 nucleosome internal standards. We then eluted the captured nucleosomes from streptavidin resin

75 by cleaving the antibody with HRV 3C endoprotease ${ }^{55}$ and, with this eluent, conducted a second

76 pulldown against H3K27me3 with a conventional antibody. This method eluted material from

77 the primary pulldown more efficiently (Extended Data Fig. 1d), resulting in 1000-2500x higher

78 enrichment of the target over the published methods (Fig. 1b, Extended Data Fig. 1a). This

79 improvement enabled genome-wide measurement of bivalency HMD (Fig. 1c), representing the

80 proportion of nucleosomes at a given locus modified with both H3K4me3 and H3K27me3, using

81 the trans-bivalent nucleosome standards ${ }^{56}$ as the calibrant (Extended Data Fig. 1e, 2;

82 Supplementary Note 1).

\section{Bivalency through differentiation}

85 With reICeChIP, we sought to study the role of bivalency in development by tracking its changes

86 across a differentiation pathway that was used in several classic studies of bivalency ${ }^{16,18,57}$ :

87 differentiation from naïve mESCs ${ }^{57}$ through the primed mESC state ${ }^{57}$ to NPCs. In naïve mESCs,

88 we noted that bivalency was far more widespread than previously reported (Fig. 2a-b); rather

89 than 1000 bivalent genes in naïve $\operatorname{mESCs}^{57}$, we observed at least $10 \%$ bivalency HMD at most

90 promoters (25768/42622), with almost 5000 promoters bearing bivalency at more than 50\% of

91 their nucleosomes (Fig. 2a,c; Supplementary Notes 2, 3). This trend is recapitulated with primed 
92 mESCs, with the consensus set of bivalent promoters representing fewer than 2000

93 genes ${ }^{18,22,35,58}$, as compared to more than 25,000 that are $>25 \%$ bivalent in our analysis.

Even more striking were the changes in bivalency across this differentiation scheme.

95 Previous studies suggested that bivalency largely disappears upon differentiation to NPCs ${ }^{16,18-20}$.

96 However, we found the opposite; promoter bivalency increases upon differentiation (Fig. 2d-e;

97 Extended Data Fig. 3a-b), with thousands more genes meeting bivalency HMD thresholds

98 relative to naïve mESCs (Fig. 2c). Similarly, we find that bivalent domains do not resolve upon

99 differentiation; tracking bivalent genes from naïve mESCs through differentiation, we observe

100 that bivalency is higher at these same promoters in primed mESCs and NPCs (Fig. 2f; Extended

101 Data Fig. 3c-f). As previously reported, primed mESCs have the most bivalency, likely related to

102 the high level of promoter H3K27me3 in this state ${ }^{57}$ (Fig. 2d). Accordingly, there are 27\% fewer

103 bivalent genes in NPCs than in primed mESCs (Fig. 2e). However, this decrease is nowhere near

104 the previously reported decrease of $92 \%^{18}$, and bivalent genes from primed mESCs remain

105 highly bivalent in NPCs (Extended Data Fig. 3g-h). Collectively, these data suggest that

106 bivalency is far more widespread in this system than previously appreciated and remains

107 elevated through differentiation, rather than resolving to one of the two monovalent states.

To investigate this discrepancy with the literature, we compared promoters identified as

109 bivalent by other studies ${ }^{18,20,35}$ to ours. The previously identified genes had $50-100 \%$ more

110 H3K27me3 than do most bivalent genes in our set (Extended Data Fig. 4a-b), suggesting that the

111 previous studies undersampled H3K27me3 and thus could only identify regions with high

112 H3K27me3 as bivalent. Accordingly, H3K27me3 dominant bivalent genes had the greatest

113 proportional overlap with these canonical bivalent loci compared to other dominance classes (i.e.

114 whether the bivalent genes have excess H3K27me3, excess H3K4me3, or roughly equal levels as 
115 measured by independent ICeChIP experiments for these two marks; Extended Data Fig. 4c).

116 The common practice of measuring bivalency as regions of overlapping H3K4me3 and

117 H3K27me3 is also problematic, even with calibrated data ${ }^{46}$; many promoters with high

118 H3K4me3 and H3K27me3 bear less than 25\% bivalency (Extended Data Fig. 4d). Notably, even

119 for the previously identified bivalent genes, bivalency still increases relative to naïve mESCs

120 upon differentiation. And in our datasets, this holds true across modification dominance classes -

121 even the H3K27me3 dominant bivalent genes, which most closely resemble the canonically

122 bivalent loci (Extended Data Figs. 4-5). To the extent that any bivalency class resolves from

123 naïve mESCs to NPCs, the largest set of genes is from the H3K4me3 dominant bivalent genes ( $p$

$124=1.78 \times 10^{-133}$; Fig. 2g), despite its minimal overlap with the canonical bivalent loci (Extended

125 Data Fig. 4c).

Having found that bivalency is unexpectedly common and persistent in early

127 differentiation, we investigated the enzyme complexes that could potentially account for this

128 ubiquity. Previous work suggested that H3K27me3 and H3K4me3 each inhibit deposition of the

129 other ${ }^{49,56,59,60}$, particularly when symmetric (Supplementary Note 4), raising questions as to

130 whether the pervasive bivalency we observe is plausible. To address this concern, we performed

131 histone methyltransferase (HMTase) assays with Set1B and the full panel MLL-family core

132 complexes (MLL1, MLL2, MLL3, MLL4), which collectively account for the bulk of H3K4

133 methylation in humans ${ }^{61}$. We find that these complexes all tolerate a wide spectrum of

134 H3K27me3-decorated nucleosomes (Extended Data Fig. 6), indicating that the formation of

135 bivalent nucleosomes is not precluded by allosteric modulation of H3K4me3 installation by core 136 factors. Although it has been suggested that Set1 $\mathrm{a}^{62}, \mathrm{Mll}^{63}$, Ezh1 ${ }^{64}$, and Ezh2 ${ }^{65}$ are all important

137 for establishing bivalency, only Mll2 appears to be sensitive for identifying bivalent promoters in 
naïve mESCs, with none showing high specificity for the same (Extended Data Fig. 7). Together,

139 these data support the proposed specialized role for Mll2 in bivalency ${ }^{63}$, indicate a pleiotropic

140 role for PRC2 beyond its role in establishing bivalency, and provide plausible enzymatic avenues

141 to the prevalent bivalency we observe by reICeChIP.

143 Bivalency, gene expression, and ontology

144 A key pillar of the bivalency hypothesis is that bivalent promoters are associated with

145 transcriptionally repressed genes poised to either be activated or terminally silenced upon

146 differentiation ${ }^{16,18,21,22}$. However, bivalency is not solely found at genes with low expression in

147 any of our measurements (Fig. 3a; Extended Data Fig. 8a-b). Rather, bivalent genes had higher

148 average expression than did non-bivalent genes or the set of all genes, and these genes display

149 modestly higher average expression through differentiation (Fig. 3a), with bivalency remaining

150 similar across most gene expression deciles (Extended Data Fig. 8c). Bivalency associated

151 similarly with bulk gene expression (Fig. 3b) and the proportion of cells expressing the

152 associated transcripts in single cell RNA-seq (Fig. 3c), suggesting that the association of

153 bivalency with higher-expressed genes is not solely driven by intercellular heterogeneity.

154 Consistent with previous observations ${ }^{18}$, bivalency was higher at promoters with high CpG

155 content (Extended Data Fig. 8d) and associated with lower DNA methylation compared to non-

156 bivalent genes (Extended Data Fig. 8e, also holds for each dominance class). These data all

157 suggest that bivalent genes are more highly expressed than non-bivalent genes as a whole, and

158 this latter class is seemingly more subject to regulation by DNA methylation. 
161 different bivalency and non-bivalency classes for differentially expressed genes (DEGs;

162 Supplementary Note 5). Counter to the bivalency hypothesis and previous results ${ }^{16,18,21}$, we

163 found that bivalency was a very poor marker of DEGs; from naïve mESCs to NPCs, bivalency

164 was roughly as sensitive and specific for identifying DEGs as was a lack of bivalency (Fig. 3d).

165 Though H3K27me3-dominant bivalent genes showed an increase in average gene expression

166 (Extended Data Fig. 8f-g), this class still only had 60\% specificity for identifying DEGs, with

167 very low sensitivity (Fig. 3d). Promoters of DEGs and non-DEGs from naïve mESCs to NPCs

168 have highly similar histone modification metaprofiles in naïve mESCs (Fig. 3e-f) and across

169 differentiation (Extended Data Fig. 8h-k). Comparison of primed mESCs to NPCs displayed

170 similar trends (Fig. 3g-h); though sensitivity was higher because most genes are bivalent in

171 primed mESCs, the specificity remained similar between bivalent and non-bivalent genes.

172 Interestingly, whether genes were upregulated, downregulated, or non-DEGs, bivalency still

173 increased over differentiation (Extended Data Fig. 8h-k). Collectively, these analyses show that

174 bivalency is neither sensitively nor specifically associated with poised DEGs in this system.

We next examined whether bivalency is primarily associated with developmental genes, a

176 central tenet of the original model ${ }^{16,18}$. The first ICeChIP study indirectly hinted that there may

177 be at least two classes of bivalent promoters: an H3K27me3 dominant class associated with

178 developmental genes, and an H3K4me3 dominant class enriched for metabolic genes ${ }^{46}$. Direct

179 measurements of bivalency herein unambiguously demonstrate this phenomenon more broadly

180 (Fig. 2a, 3i). Overall, bivalent genes are enriched for a broad range of ontology terms, including

181 developmental, metabolic, and immune system process genes (Fig. 3i-j), with nearly identical

182 bivalency profiles in naïve mESCs (Fig. 3i; Extended Data Fig. 9a). These classes all not only

183 retained, but increased bivalency into NPCs - even immune system process genes, despite being 
184 seemingly unrelated to neuronal development. We only found 543 genes that did obey the classic

185 bivalency model (Fig. 3k), representing less than 5\% of the bivalent genes from naïve mESCs,

186 with little difference in bivalency between upregulated and downregulated genes (Extended Data

187 Fig. 9b). Interestingly, these genes were most significantly enriched for metabolic rather than

188 developmental genes (Fig. 3k). Taken together, these data suggest that bivalency is neither

189 primarily nor specifically associated with developmental genes in this system.

\section{Predicting DEGs with histone PTMs}

192 The premise of the bivalency hypothesis is that the coexistence of H3K4me3 and H3K27me3

193 synergistically provides additional predictive information about the associated genes upon

194 differentiation beyond that provided by H3K4me3 and H3K27me3 alone. With quantitative

195 measurements of these modifications, this hypothesis can be tested by modelling. We first

196 determined which individual parameters best identified DEGs by measuring the area under the

197 curve (AUC) of receiver operator characteristic (ROC) curves of parameter thresholds. Of the

198 individual histone modifications, H3K4me3 levels were best for identifying DEGs, with the

199 highest AUC of the ROC (Fig. 4a; Extended Data Fig. 10a). Bivalency was less predictive of

200 DEGs than were either the log ratio of H3K27me3 and H3K4me3 or DNA methylation (Fig. 4a;

201 Extended Data Fig. 10a). And in primed mESCs, far from being predictive of poised genes,

202 bivalency was inversely associated with DEGs upon differentiation to NPCs (Extended Data Fig.

203 10a).

204 If bivalency provides additional information over H3K4me3 and H3K27me3, then a

205 model without bivalency will be markedly less explanatory than a model with bivalency. To test

206 this, we conducted logistic regressions with linear models to identify parameters most important 
207 for identifying DEGs. Bayes Information Criterion analyses preliminarily hinted that bivalency

208 provided minimal information to this end (Extended Data Fig. 10b; Supplementary Note 6). To

209 more definitively identify whether bivalency provides meaningful predictive information, we

210 conducted hold-out cross-validation on models with H3K4me3, H3K27me3 and either nothing

211 else, bivalency, H3K9me3, or DNA methylation (Fig. 4b; Extended Data Fig. 10c;

212 Supplementary Note 6). Parameters other than H3K4me3 and H3K27me3 barely improved

213 model accuracy by two separate metrics (Fig. 4c-d; Extended Data Fig. 10d-e; Supplementary

214 Note 4), suggesting that those parameters provide virtually no additional information content to

215 identify DEGs. These data suggest that, in this developmental system, there is little evidence that

216 bivalency has emergent properties in identifying poised genes beyond the combined independent

217 properties of H3K4me3 and H3K27me3.

219 Discussion

220 The bivalency hypothesis is one of the more influential ideas in epigenetics and molecular

221 developmental biology. Persistent interest over the years coupled with widespread deployment

222 and acceptance of sub-optimal bivalency measurement methods has ossified the hypothesis into

223 dogma that extends well beyond any of the experimental data that informed it.

However, this coalescence has not been reached based on functional assays. Indeed, to

225 the extent that functional validation of the bivalency model has been attempted, it has primarily

226 been through deletion of enzymes with pleiotropic effects and functions throughout the genome

227 beyond installation of bivalency ${ }^{35,63,66,67}$. Overwhelmingly, the prevailing views on the role of

228 bivalency are derived from ChIP experiments. However, ChIP protocols ${ }^{68}$ and antibodies ${ }^{47,69-72}$

229 are often highly susceptible to off-target pulldown, and uncalibrated ChIP without exogenous 
230 normalization can distort signal and the ability to compare experiments ${ }^{46,47,73}$, leading to spurious

231 conclusions $^{47}$. From the quantitative and specific measurements we made with reICeChIP, we

232 fear that this has been the case with the bivalency hypothesis, at least as far as these analyses in

233 early mESC differentiation permit.

234 It has been held that bivalency is present at a small, restricted set of promoters early in

235 development; we find that bivalency is widespread, with many thousands of promoters

236 displaying high bivalency levels. It has been held that bivalency primarily exists early in

237 development and resolves upon differentiation; we find that bivalency persists at least through

238 the NPC stage and increases over baseline in that span. It has been held that bivalency

239 demarcates poised, developmental genes associated with lineage commitment; we find that

240 bivalency is neither sensitively nor specifically associated with developmental nor differentially

241 expressed genes - and, at worst, may be inversely associated with the latter. Moreover, bivalent

242 genes are predominantly not poised in an off state, but are more highly expressed than those that

243 are not bivalent. All told, we find little evidence that bivalency provides more information in

244 predicting poised gene status than do H3K4me3 and H3K27me3 in an independently additive

245 manner in this system, raising questions as to whether it represents any more than a coincidental

246 overlap of the aforementioned two marks.

Our study is not without caveats. First, we are only able to comment meaningfully on the

248 differentiation paradigm presented here; we cannot definitively infer that these results will hold

249 for the other developmental or clinical contexts. Although the original studies on bivalency

250 indicated that bivalency almost entirely disappeared by the NPC stage ${ }^{16,18}$, this stage is not

251 terminally differentiated, so it is possible that bivalency could resolve in later stages of

252 differentiation. Future studies will be needed to address this possibility in other developmental 
253 contexts. Second, though the extant evidence suggests that only trans-bivalency is present at

254 meaningful levels, our method cannot selectively distinguish between cis-, trans-, and

255 intermediate bivalency conformations (Supplementary Note 1).

256 The reICeChIP method is not inherently restricted to the study of H3K4me3/H3K27me3

257 bivalency. With cleavable recombinant affinity reagents targeting other histone modifications ${ }^{53,74}$

258 it could be used to quantify other combinatorial modification patterns ${ }^{75-78}$ or modification

259 symmetry.

Without serious changes to the standards of ChIP, the limitations of conventional ChIP-

261 seq will continue to pose an existential challenge to the field. Indeed, the divergence between our

262 observations of bivalency and those in the literature can be attributed to the historical lack of

263 tools needed to make quantitative and specific measurements; in that context, the experimental

264 designs and interpretations of the past were reasonable. Fortunately, such tools now exist. And as

265 we have shown in this work, these methods offer a chance for the field to critically evaluate its

266 orthodox models and pave the way for new insights on the chromatin determinants of cell

267 identity and the regulation of development. 


\section{Figure Captions}

269 Fig. 1 | Workflow and evaluation of reICeChIP-seq. (a) Schematic of reICeChIP-seq. The 270 recombinant $\alpha$-H3K4me3 Fab 304M3-B achieves high affinity by "clasping" the histone tail

271 between two Fab molecules ${ }^{53}$, a binding mode readily achieved by multiple copies of the Fab

272 presented on a bead, but not by the Fab in solution. Thus, protease cleavage not only elutes

273 nucleosomes from the beads but also likely from the Fab complex. (b) Enrichment of different

274 barcoded nucleosomes in reICeChIP-seq ( $\mathrm{n}=3$ biological replicates). Error bars represent S.D. (c)

275 Representative line plot showing histone modification density of H3K4me3, H3K27me3, and

276 bivalency ICeChIP-seq presented with 95\% confidence intervals (lighter shade) and input read

277 depth in naïve mESCs. Bivalency is calibrated to the trans-bivalency nucleosome standard and

278 corrected for off-target H3K9me3 pulldown.

Fig. 2 | Bivalency is widespread and does not resolve over differentiation. (a) Bivalency,

281 H3K4me3, and H3K27me3 at all Refseq promoters in naïve mESCs, with relative enrichment of

282 GO terms. Genes are rank ordered by bivalency HMD at promoter, defined as the region from 0

283 to +400 bp relative to the TSS. (b) Representative locus view of H3K4me3, H3K27me3, and

284 bivalency at promoters in naïve mESCs (top), primed mESCs (centre), and NPCs (bottom),

285 presented on the same scale of 0-125\% HMD. (c) Number of promoters with bivalency HMDs

286 above the given thresholds in each cell type out of a total of 42,622 Refseq promoters. (d)

287 Metaprofiles of H3K4me3, H3K27me3, and bivalency at all promoters in naïve mESCs, primed

288 mESCs, and NPCs. Heatmaps for primed mESCs and NPCs are presented in Extended Data Fig.

289 3b. (e) Distribution of bivalency HMDs at all Refseq promoters in three cell states, zoomed to

290 below 125\% HMD. Overall, 99.5\% of naïve promoters, 87.3\% of primed promoters, and 91.6\% 
291 of NPC promoters have an HMD below 100\%. Full plot in Extended Data Fig. 3a. (f)

292 Metaprofiles of H3K4me3, H3K27me3, and bivalency at promoters identified as bivalent in

293 naïve mESCs (25\% HMD threshold), tracked from naïve mESCs to primed mESCs to NPCs.

294 Heatmaps for bivalency are presented in Extended Data Fig. 3f. (g-h) Alluvial plots of

295 dominance and bivalency of genes from (g) naïve mESCs to NPCs or (h) primed mESCs to

296 NPCs. Bivalency [>25\% HMD] can be subcategorized into dominance classes by independent

297 ICeChIP for the constituent marks, with H3K27me3 in excess (H3K27me3/H3K4me3 > $e^{1}$ ),

298 H3K4me3 dominant (H3K27me3/H3K4me3 $<e^{-1}$ ), or intermediate ratios (no dominance). (i)

299 Bivalency metaprofiles for gene subsets indicated in panel (h) from -3kb to $+3 \mathrm{~kb}$ relative to the TSS. **** $p<2.2 \times 10^{-16}$.

Fig. 3 | Bivalency is neither sensitive nor specific for poised nor developmental genes. (a)

303 Violin plots of gene expression ${ }^{79}$ for all genes in naïve mESCs, non-bivalent genes $(<25 \%$

304 HMD) in naïve mESCs, and bivalent genes (>25\% HMD) tracked from naïve mESCs to the

305 same genes in the indicated lineages. Significance computed by Welch's two-tailed $t$-test. (b)

306 Gene expression vs. HMD for H3K4me3, H3K27me3, and bivalency (genes are binned into

307 HMD deciles). (c) Proportion of actively transcribing cells by single-cell RNA-seq ${ }^{80}$ vs. HMD

308 for H3K4me3, H3K27me3, and bivalency (genes are binned into HMD deciles). (d) Sensitivity

309 and specificity (Supplementary Note 5) of bivalent and non-bivalent genes in naïve mESCs

310 identifying differentially expressed genes (DEGs) from the naïve state to the NPC state. (e)

311 Metaprofiles of H3K4me3, H3K27me3, and bivalency and (f) heatmaps of bivalency in naïve

312 mESCs at DEGs and non-DEGs relative to NPCs. (g) Sensitivity and specificity of bivalent and

313 non-bivalent genes in primed mESCs identifying DEGs from the primed state to the NPC state. 
314 (h) Metaprofiles of H3K4me3, H3K27me3, and bivalency in primed mESCs at DEGs and non-

315 DEGs. (i) Gene ontology term enrichment of H3K27me3-dominant bivalent genes, H3K4me3-

316 dominant bivalent genes, or bivalent genes with no clear dominance (q-value two-tailed Fisher

317 hypergeometric test). (j) Metaprofiles of H3K4me3, H3K27me3, and bivalency in naïve mESCs

318 at developmental and metabolic genes. (k) Gene ontology term enrichment of genes following

319 the classic bivalency model: DEGs that lose bivalency from naïve mESCs (>25\% HMD) to

320 NPCs (<10\% HMD). Significance computed by two-tailed Fisher hypergeometric test. * $q<$

$321 \quad 0.05 . * * q<0.01 . * * * * p$ or $q<2.2 \times 10^{-16}$.

322

323 Fig. 4 | Bivalency does not provide appreciably more information than H3K4me3 and

324 H3K27me3 alone for DEG prediciton. (a) Receiver operator characteristic (ROC) curves for

325 identifying DEGs from naïve mESCs to NPCs by H3K4me3, H3K9me3, H3K27me3, bivalency,

$326 \ln (\mathrm{H} 3 \mathrm{~K} 27 \mathrm{me} / \mathrm{H} 3 \mathrm{~K} 4 \mathrm{me} 3)$, or DNA methylation in naïve mESCs. For each point, parameter

327 value threshold used to compute true positive rate (TPR) and false positive rate (FPR) is

328 indicated by the colour. Traits with thresholds identifying non-DEGs rather than DEGs are

329 marked with “rev.” (b) Legend for generalized linear models (GLMs) in panels c-d. (c) Accuracy

330 of trivial model and GLMs by threshold accuracy (gene identified as DEG if logistic regression >

331 0.5; left) and by ROC area under curve (right). (d) ROC curves for identifying DEGs from naïve

332 mESCs to NPCs by different GLMs. For each point, logistic regression threshold value used to

333 compute TPR and FPR is indicated by the colour. 


\section{References}

927 1. Luger, K., Mäder, A. W., Richmond, R. K., Sargent, D. F. \& Richmond, T. J. Crystal

928 structure of the nucleosome core particle at 2.8 A resolution. Nature 389, 18 (1997).

$929 \quad 2 . \quad$ Strahl, B. D. \& Allis, C. D. The language of covalent histone modifications. Nature 403,

$930 \quad 41-45(2000)$.

$931 \quad 3 . \quad$ Kouzarides, T. Chromatin Modifications and Their Function. Cell 128, 693-705 (2007).

$932 \quad 4 . \quad$ Bannister, A. J. \& Kouzarides, T. Regulation of chromatin by histone modifications. Cell

933 Res. 21, 381-395 (2011).

934 5. Santos-Rosa, H. et al. Active genes are tri-methylated at K4 of histone H3. Nature 419, 935 407-411 (2002).

936 6. Wysocka, J. et al. A PHD finger of NURF couples histone H3 lysine 4 trimethylation

937 with chromatin remodelling. Nature 442, 86-90 (2006).

938 7. Heintzman, N. D. et al. Distinct and predictive chromatin signatures of transcriptional

939 promoters and enhancers in the human genome. Nat. Genet. 39, 311-318 (2007).

940 8. Guenther, M. G., Levine, S. S., Boyer, L. A., Jaenisch, R. \& Young, R. A. A Chromatin

941 Landmark and Transcription Initiation at Most Promoters in Human Cells. Cell 130, 77-88

942 (2007).

943 9. Vermeulen, M. et al. Selective Anchoring of TFIID to Nucleosomes by Trimethylation of

944 Histone H3 Lysine 4. Cell 131, 58-69 (2007).

945 10. Lauberth, S. M. et al. H3K4me3 Interactions with TAF3 Regulate Preinitiation Complex

946 Assembly and Selective Gene Activation. Cell 152, 1021-1036 (2013). 
947 11. Ringrose, L., Ehret, H. \& Paro, R. Distinct Contributions of Histone H3 Lysine 9 and 27

948 Methylation to Locus-Specific Stability of Polycomb Complexes. Mol. Cell 16, 641-653 (2004).

949 12. Boyer, L. A. et al. Polycomb complexes repress developmental regulators in murine

950 embryonic stem cells. Nature 441, 349-353 (2006).

951 13. O’Carroll, D. et al. The Polycomb-Group GeneEzh2 Is Required for Early Mouse

952 Development. Mol. Cell. Biol. 21, 4330-4336 (2001).

953 14. Pasini, D., Bracken, A. P., Jensen, M. R., Lazzerini Denchi, E. \& Helin, K. Suz12 is

954 essential for mouse development and for EZH2 histone methyltransferase activity. EMBO J. 23, 955 4061-4071 (2004).

956 15. Pasini, D., Bracken, A. P., Hansen, J. B., Capillo, M. \& Helin, K. The Polycomb Group 957 Protein Suz12 Is Required for Embryonic Stem Cell Differentiation. Mol. Cell. Biol. 27, 37699583779 (2007).

959 16. Bernstein, B. E. et al. A Bivalent Chromatin Structure Marks Key Developmental Genes 960 in Embryonic Stem Cells. Cell 125, 315-326 (2006).

961 17. Azuara, V. et al. Chromatin signatures of pluripotent cell lines. Nat. Cell Biol. 8, 532$962538(2006)$

963 18. Mikkelsen, T. S. et al. Genome-wide maps of chromatin state in pluripotent and lineage964 committed cells. Nature 448, 553-560 (2007).

965 19. Gifford, C. A. et al. Transcriptional and Epigenetic Dynamics during Specification of 966 Human Embryonic Stem Cells. Cell 153, 1149-1163 (2013).

967 20. Xie, W. et al. Epigenomic Analysis of Multilineage Differentiation of Human Embryonic 968 Stem Cells. Cell 153, 1134-1148 (2013). 
969 21. Voigt, P., Tee, W.-W. \& Reinberg, D. A double take on bivalent promoters. Genes Dev.

$970 \quad 27,1318-1338$ (2013).

971 22. Blanco, E., González-Ramírez, M., Alcaine-Colet, A., Aranda, S. \& Di Croce, L. The

972 Bivalent Genome: Characterization, Structure, and Regulation. Trends Genet. 36, 118-131

973 (2020).

974 23. Kanayama, K. et al. Genome-Wide Mapping of Bivalent Histone Modifications in

975 Hepatic Stem/Progenitor Cells. Stem Cells Int. 2019, e9789240 (2019).

976 24. Zhou, Y. et al. Bivalent Histone Codes on WNT5A during Odontogenic Differentiation.

977 J. Dent. Res. 97, 99-107 (2018).

978 25. Burney, M. J. et al. An epigenetic signature of developmental potential in neural stem

979 cells and early neurons. STEM CELLS 31, 1868-1880 (2013).

980 26. Tanimura, K., Suzuki, T., Vargas, D., Shibata, H. \& Inagaki, T. Epigenetic regulation of

981 beige adipocyte fate by histone methylation. Endocr. J. 66, 115-125 (2019).

982 27. Dhar, S. S. et al. An essential role for UTX in resolution and activation of bivalent 983 promoters. Nucleic Acids Res. 44, 3659-3674 (2016).

984 28. Abraham, B. J., Cui, K., Tang, Q. \& Zhao, K. Dynamic regulation of epigenomic 985 landscapes during hematopoiesis. BMC Genomics 14, 193 (2013).

986 29. Seenundun, S. et al. UTX mediates demethylation of H3K27me3 at muscle-specific 987 genes during myogenesis. EMBO J. 29, 1401-1411 (2010).

988 30. Cui, K. et al. Chromatin Signatures in Multipotent Human Hematopoietic Stem Cells 989 Indicate the Fate of Bivalent Genes during Differentiation. Cell Stem Cell 4, 80-93 (2009). 
990 31. Dahl, J. A., Reiner, A. H., Klungland, A., Wakayama, T. \& Collas, P. Histone H3 Lysine

99127 Methylation Asymmetry on Developmentally-Regulated Promoters Distinguish the First Two

992 Lineages in Mouse Preimplantation Embryos. PLOS ONE 5, e9150 (2010).

993 32. Vastenhouw, N. L. et al. Chromatin signature of embryonic pluripotency is established 994 during genome activation. Nature 464, 922-926 (2010).

995 33. Vastenhouw, N. L. \& Schier, A. F. Bivalent histone modifications in early

996 embryogenesis. Curr. Opin. Cell Biol. 24, 374-386 (2012).

997 34. Alder, O. et al. Ring1B and Suv39h1 delineate distinct chromatin states at bivalent genes

998 during early mouse lineage commitment. Development 137, 2483-2492 (2010).

999 35. Mas, G. et al. Promoter bivalency favors an open chromatin architecture in embryonic

1000 stem cells. Nat. Genet. 50, 1452-1462 (2018).

1001 36. Denholtz, M. et al. Long-Range Chromatin Contacts in Embryonic Stem Cells Reveal a

1002 Role for Pluripotency Factors and Polycomb Proteins in Genome Organization. Cell Stem Cell

1003 13, 602-616 (2013).

1004 37. Vieux-Rochas, M., Fabre, P. J., Leleu, M., Duboule, D. \& Noordermeer, D. Clustering of

1005 mammalian Hox genes with other H3K27me3 targets within an active nuclear domain. Proc.

1006 Natl. Acad. Sci. 112, 4672-4677 (2015).

1007 38. Kundu, S. et al. Polycomb Repressive Complex 1 Generates Discrete Compacted

1008 Domains that Change during Differentiation. Mol. Cell 65, 432-446.e5 (2017).

1009 39. Messier, T. L. et al. Oncofetal Epigenetic Bivalency in Breast Cancer Cells: H3K4 and 1010 H3K27 Tri-Methylation as a Biomarker for Phenotypic Plasticity. J. Cell. Physiol. 231, 2474$10112481(2016)$ 
1012 40. Kaukonen, D. et al. Analysis of H3K4me3 and H3K27me3 bivalent promotors in HER2+

1013 breast cancer cell lines reveals variations depending on estrogen receptor status and significantly

1014 correlates with gene expression. BMC Med. Genomics 13, 92 (2020).

1015 41. Dunican, D. S. et al. Bivalent promoter hypermethylation in cancer is linked to the

1016 H327me3/H3K4me3 ratio in embryonic stem cells. BMC Biol. 18, 25 (2020).

1017 42. Burr, M. L. et al. An Evolutionarily Conserved Function of Polycomb Silences the MHC 1018 Class I Antigen Presentation Pathway and Enables Immune Evasion in Cancer. Cancer Cell 36, 1019 385-401.e8 (2019).

1020 43. Patani, H. et al. Transition to naïve human pluripotency mirrors pan-cancer DNA 1021 hypermethylation. Nat. Commun. 11, 3671 (2020).

1022 44. Hu, D. et al. The Mll2 branch of the COMPASS family regulates bivalent promoters in 1023 mouse embryonic stem cells. Nat. Struct. Mol. Biol. 20, 1093-1097 (2013).

1024 45. Hu, D. et al. Not All H3K4 Methylations Are Created Equal: Mll2/COMPASS

1025 Dependency in Primordial Germ Cell Specification. Mol. Cell 65, 460-475.e6 (2017).

1026 46. Grzybowski, A. T., Chen, Z. \& Ruthenburg, A. J. Calibrating ChIP-Seq with

1027 Nucleosomal Internal Standards to Measure Histone Modification Density Genome Wide. Mol.

1028 Cell 58, 886-899 (2015).

1029 47. Shah, R. N. et al. Examining the Roles of H3K4 Methylation States with Systematically 1030 Characterized Antibodies. Mol. Cell 72, 162-177 (2018).

1031 48. Grzybowski, A. T., Shah, R. N., Richter, W. F. \& Ruthenburg, A. J. Native internally

1032 calibrated chromatin immunoprecipitation for quantitative studies of histone post-translational 1033 modifications. Nat. Protoc. 14, 3275-3302 (2019). 
1034 49. Voigt, P. et al. Asymmetrically Modified Nucleosomes. Cell 151, 181-193 (2012).

1035 50. Weiner, A. et al. Co-ChIP enables genome-wide mapping of histone mark co-occurrence 1036 at single-molecule resolution. Nat. Biotechnol. 34, 953-961 (2016).

1037 51. Kinkley, S. et al. reChIP-seq reveals widespread bivalency of H3K4me3 and H3K27me3 1038 in CD4 ${ }^{+}$memory T cells. Nat. Commun. 7, 12514 (2016).

1039 52. Shema, E. et al. Single-molecule decoding of combinatorially modified nucleosomes.

1040 Science 352, 717-721 (2016).

1041 53. Hattori, T. et al. Antigen clasping by two antigen-binding sites of an exceptionally

1042 specific antibody for histone methylation. Proc. Natl. Acad. Sci. 113, 2092-2097 (2016).

1043 54. Brand, M., Rampalli, S., Chaturvedi, C.-P. \& Dilworth, F. J. Analysis of epigenetic

1044 modifications of chromatin at specific gene loci by native chromatin immunoprecipitation of

1045 nucleosomes isolated using hydroxyapatite chromatography. Nat. Protoc. 3, 398-409 (2008).

1046 55. Raran-Kurussi, S., Tözsér, J., Cherry, S., Tropea, J. E. \& Waugh, D. S. Differential 1047 Temperature Dependence of Tobacco Etch Virus and Rhinovirus 3C Proteases. Anal. Biochem.

1048 436, 142-144 (2013).

1049 56. Lechner, C. C., Agashe, N. D. \& Fierz, B. Traceless Synthesis of Asymmetrically

1050 Modified Bivalent Nucleosomes. Angew. Chem. Int. Ed. 55, 2903-2906 (2016).

1051 57. Marks, H. et al. The Transcriptional and Epigenomic Foundations of Ground State

1052 Pluripotency. Cell 149, 590-604 (2012).

1053 58. Xiao, S. et al. Comparative Epigenomic Annotation of Regulatory DNA. Cell 149, 1381$10541392(2012)$ 
1055 59. Schmitges, F. W. et al. Histone Methylation by PRC2 Is Inhibited by Active Chromatin 1056 Marks. Mol. Cell 42, 330-341 (2011).

1057 60. Kim, D.-H. et al. Histone H3K27 Trimethylation Inhibits H3 Binding and Function of 1058 SET1-Like H3K4 Methyltransferase Complexes. Mol. Cell. Biol. 33, 4936-4946 (2013).

1059 61. Shilatifard, A. The COMPASS Family of Histone H3K4 Methylases: Mechanisms of

1060 Regulation in Development and Disease Pathogenesis. Annu. Rev. Biochem. 81, 65-95 (2012).

1061 62. Sze, C. C. et al. Histone H3K4 methylation-dependent and -independent functions of

1062 Set1A/COMPASS in embryonic stem cell self-renewal and differentiation. Genes Dev. 31, 1063 1732-1737 (2017).

1064 63. Denissov, S. et al. Mll2 is required for H3K4 trimethylation on bivalent promoters in 1065 embryonic stem cells, whereas Mll1 is redundant. Development 141, 526-537 (2014).

1066 64. Aoyama, K. et al. Ezh1 Targets Bivalent Genes to Maintain Self-Renewing Stem Cells in 1067 Ezh2-Insufficient Myelodysplastic Syndrome. iScience 9, 161-174 (2018).

1068 65. Béguelin, W. et al. EZH2 and BCL6 Cooperate to Assemble CBX8-BCOR Complex to 1069 Repress Bivalent Promoters, Mediate Germinal Center Formation and Lymphomagenesis.

1070 Cancer Cell 30, 197-213 (2016).

1071 66. Tan, H. K. et al. DNMT3B shapes the mCA landscape and regulates mCG for promoter

1072 bivalency in human embryonic stem cells. Nucleic Acids Res. 47, 7460-7475 (2019).

1073 67. Eckersley-Maslin, M. A. et al. Epigenetic priming by Dppa2 and 4 in pluripotency

1074 facilitates multi-lineage commitment. Nat. Struct. Mol. Biol. 27, 696-705 (2020). 
1075 68. Kasinathan, S., Orsi, G. A., Zentner, G. E., Ahmad, K. \& Henikoff, S. High-resolution 1076 mapping of transcription factor binding sites on native chromatin. Nat. Methods 11, 203-209 1077 (2014).

1078 69. Bock, I. et al. Detailed specificity analysis of antibodies binding to modified histone tails 1079 with peptide arrays. Epigenetics 6, 256-263 (2011).

1080 70. Egelhofer, T. A. et al. An assessment of histone-modification antibody quality. Nat.

1081 Struct. Mol. Biol. 18, 91-93 (2011).

1082 71. Nishikori, S. et al. Broad Ranges of Affinity and Specificity of Anti-Histone Antibodies 1083 Revealed by a Quantitative Peptide Immunoprecipitation Assay. J. Mol. Biol. 424, 391-399 1084 (2012).

1085 72. Fuchs, S. M., Krajewski, K., Baker, R. W., Miller, V. L. \& Strahl, B. D. Influence of 1086 Combinatorial Histone Modifications on Antibody and Effector Protein Recognition. Curr. Biol. 1087 21, 53-58 (2011).

1088 73. Orlando, D. A. et al. Quantitative ChIP-Seq Normalization Reveals Global Modulation of 1089 the Epigenome. Cell Rep. 9, 1163-1170 (2014).

1090 74. Hattori, T. et al. Recombinant antibodies to histone post-translational modifications. Nat. 1091 Methods 10, 992-995 (2013).

1092 75. Allis, C. D. \& Jenuwein, T. The molecular hallmarks of epigenetic control. Nat. Rev.

1093 Genet. 17, 487-500 (2016).

1094 76. Lu, C., Coradin, M., Janssen, K. A., Sidoli, S. \& Garcia, B. A. Combinatorial Histone H3 1095 Modifications Are Dynamically Altered in Distinct Cell Cycle Phases. J. Am. Soc. Mass

1096 Spectrom. 32, 1300-1311 (2021). 
1097 77. Suganuma, T. \& Workman, J. L. Signals and Combinatorial Functions of Histone

1098 Modifications. Annu. Rev. Biochem. 80, 473-499 (2011).

1099 78. Henikoff, S. Histone modifications: Combinatorial complexity or cumulative simplicity?

1100 Proc. Natl. Acad. Sci. 102, 5308-5309 (2005).

1101 79. Terranova, C. et al. Global Developmental Gene Programing Involves a Nuclear Form of

1102 Fibroblast Growth Factor Receptor-1 (FGFR1). PLOS ONE 10, e0123380 (2015).

1103 80. Xing, Q. R. et al. Parallel bimodal single-cell sequencing of transcriptome and chromatin 1104 accessibility. Genome Res. 30, 1027-1039 (2020). 


\section{Acknowledgements}

1171 We would like to thank Peter Faber, Hannah Whitehurst, and Mikayla Marchuk in the University

1172 of Chicago Functional Genomics Facility for Illumina sequencing. We would also like to thank

1173 EpiCypher, Inc. for providing some of the histone octamers for this study. A.T.G. was supported

1174 by the Harper Dissertation Prize and the Dean’s International Student Fellowship of the

1175 University of Chicago. R.N.S. was supported by the National Institutes of Health under award

1176 number T32-HD007009-45 to the University of Chicago. J. E. was supported by the National

1177 Institutes of Health under award number T32-GM007197 and R25-GM109439 to the University

1178 of Chicago. This study was supported by the National Institutes of Health, under award numbers

1179 R01-GM115945 to A.J.R. and R01-DA036887 to S.K.; and the American Cancer Society, under

1180 award number 130230-RSG-16-248-01-DMC to A.J.R.

\section{Author Contributions}

1183 A.T.G. and A.J.R. conceived of the study. Z.C. made cis-bivalent H3K4me3-H3K27me3

1184 histones. C.C.L. and B.F. constructed the trans-bivalent H3K4me3-H3K27me3 histone dimers.

1185 T.H. and S.K. provided 304M3B Fab and assisted in design of 304M3B-1HRV3C Fab. P.W.L.

1186 provided recombinant PRC2 for supporting experiments. A.T.G. developed reICeChIP,

1187 expressed and purified 304M3B-1HRV3C Fab, and conducted methyltransferase assays with

1188 input and oversight from A.J.R. A.T.G. cultured naïve mESCs; J.E. cultured and differentiated

1189 naïve mESCs to primed mESCs and NPCs. A.T.G. conducted reICeChIP-seq on naïve mESCs;

1190 R.N.S. conducted reICeChIP-seq on primed mESCs and NPCs. A.T.G. and R.N.S. conducted

1191 bioinformatic analysis on naïve mESCs; J.E. generated representative genome browser views.

1192 R.N.S. conducted all other bioinformatic analyses with oversight and input from A.T.G., J.E., 
1193 and A.J.R. R.N.S., A.T.G., J.E., and A.J.R. wrote the manuscript with input from the other

1194 authors.

1196 Competing Interests

1197 The authors declare competing financial interests. A.T.G., Z.C. and A.J.R hold partial

1198 intellectual property rights to ICeChIP as co-inventors on a patent filed by the University of

1199 Chicago [Patent \# US20200319204A1]). This patent is under license to EpiCypher, Inc., a

1200 commercial developer and supplier of platforms similar to ICeChIP with barcoded nucleosomes

1201 (i.e. SNAP-ChIP ${ }^{\mathrm{TM}}$ and CAP-ChIP ${ }^{\mathrm{TM}}$ ). R.N.S., A.T.G., and A.J.R. have served in a compensated

1202 consulting role to EpiCypher, Inc., and A.J.R. is a member of the Scientific Advisory Board.

1203

1204 Additional Information

1205 Supplementary Information is available for this paper.

1206 Correspondence and requests for materials should be addressed to A.J.R.

1207 Reprints and permissions information is available at http://www.nature.com/reprints. 


\section{Extended Data Figure Captions}

336 Extended Data Fig. 1 | Evaluation of sequential ChIP methods. (a) Enrichment of on- and

337 off-target nucleosome standards under sequential ChIP protocols developed by Bernstein et al. ${ }^{16}$,

338 Voigt et al. ${ }^{49}$, and Seenundun et al. $^{29}$. (b-c) Enrichment at different sequential ICeChIP steps

339 with (b) chemical denaturant elution and (c) immunoglobulin and serum elution. (d) Enrichment

340 of different nucleosome standards with ICeChIP-qPCR performed against H3K4me3,

341 H3K27me3, and bivalency, with beads showing very little retention of chromatin ( $\mathrm{n}=3$ technical

342 replicates). Error bars represent standard deviation. (e) Different configurations of bivalency on a

343 single nucleosome. Of these, only trans-bivalency has been identified by mass spectrometry ${ }^{49,81}$.

\section{Extended Data Fig. 2 | Evaluation of reICeChIP specificity and standards. (a)}

346 Representative genome browser view of H3K4me3, H3K27me3, and bivalency, shown as a

347 range of possible values by normalization to trans-bivalent (upper limit) or cis-bivalent (lower

348 limit) nucleosome standards. (b) Relative pulldown of different nucleosome standards in

349 ICeChIP-seq, normalized to the most-enriched standard. (c) Scatterplots of reads from DNA

350 barcodes applied to nucleosome standards in ICeChIP-seq. (d) Violin plots of peak breadth

351 (consecutive segment of 50bp windows overlapping promoter with >25\% HMD) for H3K4me3

352 (green) and bivalency (blue) at non-bivalent and bivalent genes (>25\% HMD) in naïve mESCs.

353 (e-f) Autocorrelation of (e) H3K4me3 and (f) bivalency HMDs between nucleosomes in naïve

354 mESCs. Nucleosomes are defined as sequential 200bp windows from the TSS. 
356 Extended Data Fig. 3 | Tracking bivalent genes through differentiation. (a) Distribution of

357 bivalency HMDs at all Refseq promoters in three cell states. (b) Heatmaps of bivalency at all

358 Refseq promoters in primed mESCs and NPCs. Genes are ordered by bivalency HMD at the

359 promoter. (c) Venn diagram showing overlap of bivalent genes (25\% HMD threshold) in naïve

360 mESCs, primed mESCs, and NPCs. (d-e) Metaprofiles of H3K4me3, H3K27me3, and bivalency

361 for bivalent genes in naïve mESCs with a (d) 10\% or (e) 50\% HMD threshold. (f) Heatmaps and

362 metaprofiles of bivalent genes from naïve mESCs. (g) Metaprofiles of H3K4me3, H3K27me3,

363 and bivalency at genes tracked from primed mESCs to NPCs for bivalent genes in primed

364 mESCs (>25\% HMD). (h) Heatmaps and metaprofiles of bivalent genes in primed mESCs that

365 are not bivalent in naïve mESCs.

Extended Data Fig. 4 | Comparing our bivalent genes to other studies. (a-b) Contingency

368 tables and metaprofiles for genes that are identified as $>25 \%$ bivalent in our study and by

369 Mikkelsen et al. ${ }^{18}$, Mas et al. ${ }^{35}$, and Xiao et al. ${ }^{58}$, wherein: (a) gene is identified as bivalent in the

370 external study if overlapping H3K4me3 and H3K27me3 peaks overlap the 0 to +400bp region of

371 a gene relative to the TSS, or (b) gene is identified as bivalent in the external study if

372 overlapping H3K4me3 and H3K27me3 peaks overlap the region from 2.5kb upstream of the TSS

373 to the end of the gene $e^{22}$. (c) Overlap of bivalent genes from external datasets (as defined in part

374 a) with each of our bivalent gene dominance classes in naïve mESCs. Significance computed by

375 two-tailed Fisher hypergeometric test. (d) Overlap of genes with bivalency HMD > 25\% and

376 with H3K4me3 + H3K27me3 HMD > 25\% in all three cell states. 

bivalent genes (>25\% HMD) in primed mESCs that are for indicated dominance classes tracked from primed mESCs to NPCs.

Extended Data Fig. 6 | Methyltransferase assays identifying potential pathways for by kinetic evaluation to be sensitive to difference in activity for this panel. Signal is corrected for background and no nucleosome substrate activity. Error bars represent standard deviation.

Extended Data Fig. 7 | HMTase peaks and bivalency. Contingency tables and metagene profiles in naïve mESCs for genes with and without overlapping HMT peaks. Ezh1 and Ezh2

395 peaks were identified as Suz12 peaks lost upon Ezh1 or Ezh2 knockout ${ }^{82}$. Set1A peaks were 396 identified by ChIP against Set1 ${ }^{62}$. Mll2 peaks were identified by ChIP against Mll2 ${ }^{45}$. 
metaprofiles in naïve mESCs at promoters binned by gene expression decile. (d) Violin plots of

401 bivalency HMD in naïve mESCs at promoters with and without CpG islands. Inset shows

402 proportion of genes that are bivalent in sets of genes classified by CpG content: high-CpG

403 promoters (HCP), intermediate-CpG promoters (ICP), and low-CpG promoters (LCP), defined as

404 previously described by Mikkelsen et al. ${ }^{18}$. Total number of genes in each class is provided as $\mathrm{n}$.

405 (e) Violin plots of DNA methylation at bivalent and non-bivalent genes (top), broken by

406 dominance class for bivalent genes (bottom). (f-g) Violin plots of gene expression in (f) non-

407 bivalent (<25\% HMD) and (g) bivalent (>25\% HMD) genes from naïve mESCs that are

408 H3K27me3 dominant (H3K27me3/H3K4me3 > $e^{1}$; left), have no clear dominance (centre), or

409 are H3K4me3 dominant (H3K27me3/H3K4me3 < $e^{-1}$; right). (h-k) Metaprofiles of H3K4me3,

410 H3K27me3, and bivalency at genes tracked from naïve mESCs to primed mESCs to NPCs for

411 (h) DEGs, (i) non-DEGs, (j) genes upregulated from naïve mESCs to NPCs, and (k) genes

412 downregulated from naïve mESCs to NPCs. ${ }^{* * * *} p<10^{-16}$ (Welch’s two-tailed t-test).

414 Extended Data Fig. 9 | Bivalency at different classes of genes. (a) Metaprofiles of H3K4me3,

415 H3K27me3, and bivalency at genes tracked from naïve mESCs to primed mESCs to NPCs for

416 bivalent genes of indicated gene ontology terms. (b) Metaprofiles of H3K4me3, H3K27me3, and

417 bivalency at genes tracked across differentiation for genes that lose bivalency at the promoters $(0$

418 to +400bp relative to TSS) from naïve mESCs (>25\% HMD) to NPCs (<10\% HMD) and are

419 upregulated (top) or downregulated (bottom) over differentiation.

421 Extended Data Fig. 10 | Modelling the additional information content provided by

422 bivalency over H3K4me3 and H3K27me3 alone. (a) ROC curves for identifying DEGs from 
423 primed mESCs to NPCs by H3K4me3, H3K9me3, H3K27me3, bivalency,

$424 \ln (\mathrm{H} 3 \mathrm{~K} 27 \mathrm{me} 3 / \mathrm{H} 3 \mathrm{~K} 4 \mathrm{me})$, or DNA methylation in primed mESCs. For each point, parameter

425 value threshold used to compute true positive rate (TPR) and false positive rate (FPR) is

426 indicated by the colour. Traits with thresholds identifying non-DEGs rather than DEGs are

427 marked with “rev.” (b) Bayes Information Criterion (BIC) for logistic models identifying DEGs

428 from naïve mESCs or primed mESCs to NPCs with different parameters. (c) Legend for

429 generalized linear models (GLMs). (d) Accuracy of trivial model and GLMs by threshold

430 accuracy (gene identified as DEG if logistic regression > 0.5; left) and by ROC area under curve

431 (right). (e) ROC curves for identifying DEGs from primed mESCs to NPCs by different GLMs.

432 For each point, logistic regression threshold value used to compute TPR and FPR is indicated by

433 the colour. 


\section{Supplementary Notes}

\section{Supplementary Note 1}

437 As each nucleosome has two H3 protomers, there are several different configurations of

438 bivalency that a bivalent nucleosome can theoretically adopt, each with a different avidity for

439 ChIP pulldown with immobilized antibody. At one extreme, with the highest avidity, is the

440 symmetric cis-bivalency form, where both H3K4 and both H3K27 residues are trimethylated

441 (Extended Data Fig. 1e). This nucleosome has the most epitopes for antibody binding and will

442 thus have the highest avidity in pulldown reflected in apical pulldown efficiency (Extended Data

443 Fig. 1d). At the other extreme, with the lowest avidity, is the trans-bivalency form, where single

444 H3K4me3 and H3K27me3 marks decorate different histone tails (Extended Data Fig. 1e). This

445 has the fewest epitopes for antibody binding and will thus have no avidity in pulldown.

447 because we cannot separately measure trans-bivalency, symmetric cis-bivalency, nor any

448 intermediate states, it is impossible for us to definitively state whether a given locus with a given

449 HMD has relatively few nucleosomes that are symmetric cis-bivalent or whether it has relatively

450 many nucleosomes that are trans-bivalently modified. To accommodate for this limitation, we

451 include two different bivalent calibrants in our set of nucleosome standards: one that is

452 symmetric cis-bivalent and one that is trans-bivalent. The bivalency sequential ChIP can then be

453 normalized to either one of these standards, and because these two cases represent the limits of

454 pulldown avidity, normalization to these calibrants will define the theoretical "range" in which

455 true bivalency HMD (i.e. the proportion of nucleosomes with some bivalent configuration) exists

456 (Extended Data Fig. 1e). We note that, because the signal from calibration to these standards are

457 scalar multiples of each other, we cannot uniquely distinguish these two configurations in the 
genome. Absent any prior information about the dominant configuration of bivalency, the

459 proportion of bivalently modified nucleosomes at a given locus will exist in the range defined by calibration to symmetric cis- or trans-bivalent standards (Extended Data Fig. 2a). spectrometry evidence that H3K4me3 and H3K27me3 exist on the same histone tail, despite

463 specific enrichment for these marks and sensitive detection limits ${ }^{49,81}$, suggesting that

464 configurations other than trans-bivalency are at most, extremely minor in abundance. Second,

465 the scarcity of these cis-tail modifications is consistent with the bioschemical literature prior to

466 this work that suggests the biogenesis of these cis-tail modifications is enzymatically challenging

467 due to antagonistic allosteric effects (see Supplementary Note 4). Third, even if symmetric cis-

468 bivalency does exist at some loci, for the purposes of tracking changes in bivalency across

469 differentiation, we can still observe an increase or decrease in bivalency by this calibration

470 method; we simply cannot precisely discern whether the effect is driven by nucleosomes

471 gaining/losing trans-bivalency, cis-bivalency, or some combination of the two. The overall

472 amount of bivalency would still increase or decrease in all those scenarios, and so long as our

473 choice of calibrant remains consistent, we can still measure that change regardless of the

474 calibrant that we use for our normalization. Therefore, though we have generated datasets using

475 both calibrants, we present analyses of our reICeChIP bivalency pulldowns calibrated to the 476 trans-bivalent standards.

479 Throughout this study, we have defined gene promoters to be the region from 0 to $+400 \mathrm{bp}$ 480 relative to the TSS, representing the +1 and +2 nucleosomes of each gene. These nucleosomes 
481 tend to be well-positioned ${ }^{83}$ and, accordingly, are most likely to provide us with adequate read

482 depth to robustly quantify each histone modification. This definition is conservative; we find that

483 H3K4me3 and bivalent domains, which tend to be peak-like, have a median breadth of 550bp at

484 bivalent genes (Extended Data Fig. 2d).

The width of these domains raises an important point regarding the measurement of

486 histone modification density as a continuous variable. At a given nucleosome in a single allele of

487 a single cell, there are only three possible states for a histone modification: symmetric,

488 asymmetric or not present. However, nucleosome readers do not typically bind only a single

489 nucleosome at a single position; rather, the local density of the modification across multiple

490 nucleosomes is crucial in localizing these effectors through multivalent avidity-based

491 interactions ${ }^{84-87}$. Indeed, we find that the HMD across sequential nucleosomes relative to the

492 TSS is well autocorrelated (Extended Data Fig. 2e). This means that the interpretation of the

493 HMD across a multinucleosomal span becomes more nuanced; a given histone modification may

494 exist at one or more of those nucleosomes. Accordingly, despite the fact that a single nucleosome

495 is essentially ternary in whether it has a given histone modification or not (i.e. HMD of $0 \%$ or

496 100\%), a region spanning multiple nucleosomes could have an intermediate HMD; it is this latter

497 quantity that is most relevant for the biological function imparted to the nearby genomic regions,

498 and this is the quantity we analyse through this work.

501 For the datasets presented in this work, the vast majority of promoters have a histone

502 modification density between 0-100\%, representing the proportion of nucleosomes at those 
503 promoters with the modification of interest (Fig. 2c; Extended Data Fig. 3a). However, at some

504 loci, the measured HMD exceeds 100\%. There are several possible reasons for this.

505 The most important of these possibilities is low input depth. The ICeChIP datasets are

506 normalized to the input read depth at every genomic interval to accommodate for differences in

507 local nucleosome density when computing the HMD. However, this means that at regions that

508 are relatively nucleosome-depleted, there will be few reads in the input, meaning that the

509 denominator of the HMD computation is quite small (Methods). This increased Poisson noise in

510 these regions of low input can result in inflated apparent HMD beyond the physical limit of

511 100\%. To accommodate for this, we can compute 95\% confidence intervals for the HMD of each

512 modification at each genomic position, and these confidence intervals virtually always overlap

513 the physically possible range of HMD values (e.g., Fig. 1c). In naïve mESCs, only 0.5\% of the

514 promoters have a bivalency HMD above 100\%, and for the vast majority of these promoters

515 (86.1\%), the 95\% confidence interval error estimate ranges below 100\%. The fact the apparent

516 bivalency HMD calibrated by trans-bivalent standards, is broadly constrained to less than $100 \%$

517 further supports the idea that this choice of calibrant is appropriate and not inflationary

518 (Supplementary Note 1).

There are also several other possibilities that are more challenging to accommodate for.

520 First, some regions of the genome are known to be more artefact-prone for sequencing and

521 mapping ${ }^{88}$; if the IP sample is enriched for these sequences relative to the input, then that could

522 be disproportionately represented in the IP and have an apparent HMD greater than 100\%.

523 Second, the antibodies themselves could skew the apparent HMD. If the antibody is capturing

524 substantial off-target material, then that will result in systematic inflation of the IP, resulting in

525 an inflated HMD. Though ICeChIP barcoded nucleosome standards can help monitor off-target 
526 pulldown of some nucleosome species, we can only measure the capture of the standards that we

527 actually have spiked into the experiment. If we do not have nucleosome standards available for a

528 potential off-target modification, then we cannot definitively state that the antibody is not

529 capturing that material. In this context, that is likely most important for H3K27me3 pulldowns;

530 though we cannot state this definitively due to the lack of H3K27me2 standards, it is plausible

531 that we are pulling down some amount of H3K27me2 with these IPs, resulting in slightly inflated

532 apparent H3K27me3 HMD. However, this may not be too problematic; H3K27me2 and

533 H3K27me3 are thought to be recognized by many of the same proteins and to have highly

534 similar functions ${ }^{82}$, so the conflation of the two - if present - likely does not pose a significant

535 problem in ascribing biologic function.

On a related note, at some loci, the bivalency HMD goes below $0 \%$. In naïve mESCs,

$5378.8 \%$ of the promoters have a bivalency HMD below $0 \%$, yet for the vast majority of these

538 promoters (90.8\%), the 95\% confidence interval error estimate ranges above zero. This is

539 because we employ in silico signal-correction for the bivalency dataset to remove signal that is

540 attributable to H3K9me3. In essence, we can measure the amount of H3K9me3 pulldown in our

541 bivalency ICeChIP dataset due to nucleosome standards employed, and we can separately

542 measure the H3K9me3 HMD by a highly specific IP. We can then a linear combination

543 correction matrix to remove the signal that is attributable to directly measured H3K9me3 at these

544 loci. This method can effectively reduce the impact of modest off-target binding H3K9me3, but

545 at some loci, will result in a subzero apparent HMD due to random sampling of read depth in the

546 two distinct pulldowns employed. 
549 First, there is some nuance in the interpretation of HMD in the context of single-target ICeChIP

550 and reICeChIP. A nucleosome has two copies of each of its core histone proteins, including

551 histone H3. This means that there are two possible sites of modification on each nucleosome for

552 for each individual modification; if only one of those sites is modified, then that corresponds to

553 an HMD of 50\% because only half the possible modification sites are actually modified.

554 However, this is different for the trans-bivalency HMD; by definition, only one trans-bivalency

555 modification pattern can exist on a given nucleosome at any given time. If two "trans-bivalent"

556 modification patterns existed on the same nucleosome simultaneously, then both H3K4 and both

557 H3K27 residues would be trimethylated - which is symmetric cis-bivalency. As such, if one

558 H3K4 and one H3K27 residue are trimethylated, then 100\% of the possible trans-bivalency

559 configurations for the nucleosome of interest are satisfied, meaning that the trans-bivalency

560 HMD will be 100\%. However, in this case, the H3K4me3 and H3K27me3 HMDs will only be

$56150 \%$ because only half the modifiable residues are actually modified.

562 The other caveat is that symmetrically modified nucleosomes will be pulled down more

563 efficiently than asymmetrically modified nucleosomes due to avidity effects, as can be seen in

564 the pulldown of symmetric vs. asymmetric H3K4me3 and cis-bivalency vs. trans-bivalency

565 (Extended Data Fig. 2), and observed previously ${ }^{46}$. This means that calibration to symmetric

566 nucleosome standards will have a larger denominator in computation of HMD and thereby yield

567 lower apparent HMDs; this can also contribute to the lower apparent HMD of H3K4me3 and

568 H3K27me3 relative to trans-bivalency. Accommodating for this phenomenon would require

569 detailed profiling of asymmetric H3K4me3 (which is currently difficult due to the low quality of

570 H3K4me0 antibodies), asymmetric H3K27me3 (which is not currently possible), and

571 distinguishing between trans-bivalency and cis-bivalency (which is also not currently possible). 
572 However, as noted in Supplementary Note 1, so long as the method of calibration remains

573 consistent, increases in apparent HMD will still correspond to increases in the modification of

574 interest. Whether that increase in the target modification is due to asymmetric modification

575 becoming symmetric or due to new gain of the modification at a previously unmodified locus in

576 an instantaneous subpopulation remains unclear, but in both cases, modification density is still

577 being gained at that locus. As such, even with these caveats, we can still quantitatively compare

578 different datasets to each other as we use consistent calibration standards.

580 Supplementary Note 4

581 Intriguingly, the catalytic activity of the EZH2-PRC2 core complex on nucleosome substrates is

582 potentiated by pre-existing H3K27me $3^{89,90}$, yet inhibited by H3K4me3, particularly when

583 symmetric ${ }^{49,56,59}$. Conversely, symmetric H3K27me3 has been reported to modestly inhibit

584 several of the human COMPASS-family complexes by qualitative assays, although only SET1

585 complexes were examined at the nucleosome level ${ }^{60}$. This presents a potential concern for our

586 data - if the enzyme complexes that install these marks are mutually antagonized by the

587 opposing mark, how might the widespread bivalency we observe arise? As the PRC2 effects are

588 well established with detailed quantitative enzymology $49,56,59$, which we recapitulate (data not

589 shown), we deployed more quantitative HMTase assays with a larger panel of relevant

590 nucleosomal substrates to evaluate the COMPASS/SET1B/MLL-family core complexes for

591 allosteric modulation by preexisting marks (Extended Data Fig. 6). 


\section{Supplementary Note 5}

595 In this context, sensitivity refers to the proportion of DEGs that are represented in a specific class

596 of genes (e.g. H3K27me3-dominant bivalent genes), whereas specificity refers to the proportion

597 of that class of genes that are differentially expressed. Under the prevailing bivalency model,

598 bivalency is associated with poised genes that become upregulated or downregulated upon

599 differentiation; as such, it should have high specificity for DEGs.

\section{Supplementary Note 6}

602 The first way we evaluate different models for predicting DEGs is to compute the Bayes

603 Information Criterion (BIC). Though not definitive, this metric estimates whether addition of a

604 parameter to a model improves it more than would be expected from chance alone. When

605 comparing two models, the model with the lower BIC will tend to have more explanatory

606 parameters and/or fewer non-explanatory parameters than the model with the higher BIC. To this

607 end, if BIC increases when a parameter is added, then it can be interpreted that the parameter

608 being added contributes minimal additional explanatory power. Here, we find that adding

609 bivalency to a model increases the BIC, meaning that it is likely (though not definitively) not

610 contributing meaningfully more information in predicting DEG status in this differentiation

611 paradigm.

A more definitive way to evaluate model accuracy is to use hold-out cross-validation. In

613 this method, we split the set of all genes into two groups, one with $80 \%$ of the genes (the training

614 set) and one with $20 \%$ of the genes (the testing set). We then train our GLMs on the training set

615 and use the derived models to predict DEG status in the testing set. Hold-out cross-validation is a

616 highly effective way of testing whether a model is overfit or underfit upon addition or removal of 
617 a parameter. If model accuracy increases substantially, then that would suggest the parameter has

618 explanatory power over that provided by the other parameters. Conversely, if model accuracy

619 decreases substantially, then that suggests that the additional parameter causes overfitting.

620 Minimal changes in model accuracy suggest that the additional parameter contributes little to the 621 model over the existing parameters, positively or negatively.

There are two metrics we use to test the accuracy of the predictions in the testing set. The

623 first is by logistic regression thresholding, in which the gene is predicted to be a DEG if the

624 modelled probability is greater than 0.5 . The second is by computing the area under the receiver

625 operator characteristic curve to measure true and false positive rates using different modelled

626 probabilities as the thresholds.

627 Overall, we find that the GLM with bivalency barely changes model accuracy by either

628 metric on hold-out cross-validation, with the magnitude of change being similar to that observed

629 by instead adding H3K9me3 or DNA methylation. As such, we can interpret that none of these

630 parameters - including bivalency - meaningfully contributes to the prediction of DEGs beyond

631 what can be achieved with H3K4me3 and H3K27me3 in this system. 


\section{Methods}

634 Cell Culture

635 Naïve mouse Embryonic Stem Cells (mESCs) were grown from the mESC E14 cell line

636 (129/Ola background) ${ }^{91}$ in high glucose DMEM (Invitrogen), supplemented with 15\%(v/v) FBS

637 (Gibco), 1\%(v/v) non-essential amino acids (Gibco), 1x penicillin/streptomycin (Gibco), $0.1 \mathrm{mM}$

638 2-mercaptoethanol (Gibco), 2mM L-glutamine (Gibco), 1000 U/mL LIF (ESG1107 Millipore),

$6393 \mu \mathrm{M}$ CHIR99021 (LC Laboratories), 1 M PD0325901 (LC Laboratories), sterilized using

$640 \quad 0.1 \mu \mathrm{m}$ filter flask (Millipore), stored up to 1 week in $4^{\circ} \mathrm{C}$.

641 Primed mESCs were grown from the mESC E14 cell line (129/Ola background) ${ }^{91}$ in high

642 glucose DMEM (Invitrogen), supplemented with 15\%(v/v) FBS (Gibco), 1\%(v/v) non-essential

643 amino acids (Gibco), 1x penicillin/streptomycin (Gibco), $0.1 \mathrm{mM}$ 2-mercaptoethanol (Gibco),

644 2mM L-glutamine (Gibco), 1000 U/mL LIF (ESG1107 Millipore), sterilized using $0.1 \mu \mathrm{m}$ filter

645 flask (Millipore), stored up to 1 week in $4^{\circ} \mathrm{C}$.

646 Naïve and primed mESCs were grown on plates coated with $0.1 \%$ bovine gelatin (Sigma), grown

647 to $70-90 \%$ confluence and passaged daily at a 1:3 ratio, with a media change 3 hours before

648 passaging, supplemented with 1 vol. of fresh media 8 hours after passaging.

649 To initiate the adherent monolayer differentiation process to neuronal progenitor cells (NPCs;

650 Day 0$)^{92,93}$, naïve mESCs cells were split onto a gelatinized $6 \mathrm{~cm}$ plate at $1 \times 10^{4}$ cells/cm ${ }^{2}$ and

651 allowed to grow for 24 hours. On Day 1, the media was switched to RHB-A (Takara, Y40001)

652 and was subsequently changed every other day. On day 4, cells were split and plated onto Poly-

653 L-Ornithine, laminin-treated 6-cm plates. Prior to cell seeding the plates were treated with $0.01 \%$

654 Poly-L-Ornithine (Millipore, A004C) for at least $20 \mathrm{~min}$, followed by $5 \mathrm{ug} / \mathrm{cm}^{2}$ of laminin

655 (Fisher, CB40232) resuspended in basal RHB-A medium (Takara, Y40000). After washing off 
656 this treatment, cells were seeded in fresh RHB-A, supplemented with $10 \mathrm{ng} / \mathrm{mL}$ of bFGF

657 (PeproTech, 100-18B) and EGF (PeproTech, 315-09). Cells were then split every 4 days at $\geq$

658 20,000 cells/cm2 until an appropriate amount of NPCs were cultured for ICeChIP.

661 Human histones H3.2(C110A)K4me3, H3.2(C110A)K9me3, H3.2(C110A)K27me3,

662 H3.2(C110A)K4me3-K27me3 were made by semi-synthesis as described previously ${ }^{46,94}$.

663 Asymmetric disulfide linked histone H3K4me3 - H3K27me3 dimers were made by semi-

664 synthesis as described previously ${ }^{56}$.

\section{Octamer Reconstitution}

Symmetrical H3K4me3, H3K27me3, H3K4me3-K27me3 and H3K9me3 octamers were made as

668 previously described ${ }^{95,96}$. Briefly, equimolar amounts of histone H2A, H2B, H3 and H4 were

669 mixed to the final concentration of $1 \mathrm{mg} / \mathrm{ml}$ in unfolding buffer (50 mM Tris-HCl pH 8, 6.3 M

670 Guanidine-HCl, $10 \mathrm{mM}$ 2-mercaptoethanol, $4 \mathrm{mM}$ EDTA), subsequently they were loaded into

6713500 M.W.C.O. dialysis tubing (Pierce Snakeskin) and dialyzed in 1000 volumes of refolding

672 buffer (20 mM Tris-HCl pH 7.5, $2 \mathrm{M} \mathrm{NaCl,} \mathrm{1mM} \mathrm{EDTA,} 5 \mathrm{mM} \mathrm{DTT}$ ), overnight at $4^{\circ} \mathrm{C}$.

673 Dialyzed sample was $0.22 \mu \mathrm{m}$ filtered, and octamers were resolved by S200 gel filtration

674 chromatography (Superdex 200 10/300 GL, GE Healthcare) using refolding buffer as mobile

675 phase. Eluted octamer fractions were pooled and concentrated using centrifugal filters (Amicon

676 Ultra-4, 10k M.W.C.O., Millipore) to a final concentration of 5-15 $\mu \mathrm{M}$, diluted with 1 volume of

677 octamer storage buffer (20 mM Tris-HCl pH 7.5, 2 M NaCl, 1 mM EDTA, 5 mM DTT, 55\%

678 glycerol), and stored in $-20^{\circ} \mathrm{C}$. Concentration of octamer was measured spectroscopically using 
679 concentrator flow-through as a blank, $\varepsilon_{280 \mathrm{~nm}}=44700 \mathrm{M}^{-1} \mathrm{~cm}^{-1}, \mathrm{M}_{\mathrm{oct}} \approx 108500 \mathrm{~g}^{1} \mathrm{~mol}^{-1}$. Octamers

680 were visualized using 18\% separating (4\% stacking) discontinuous Laemmli SDS-PAGE in

681 Mini-Protean gel running system (Bio-Rad) run for 70 minutes at 22mA, 200V max.

682 Asymmetrical H3K4me3, H3K27me3 octamers were done as above with the following

683 differences. Equimolar amounts of histone H2A, H2B, H3 and H4 were mixed in unfolding

684 buffer to the total of 1-2 mg, where 90\% of histone H3 was trimethylated on Lys 4 or Lys 27 and

685 remaining 10\% were unmethylated and had His6-tag at N-terminus with TEV cleavage site.

686 Octamers were reconstituted overnight by dialysis in 1000 volumes of phosphate refolding buffer

$687\left(50 \mathrm{mM} \mathrm{Na}_{x} \mathrm{PO}_{4} \mathrm{pH} 7.5,2 \mathrm{M} \mathrm{NaCl}\right)$, at $4{ }^{\circ} \mathrm{C}$. Octamers were purified by S200 gel filtration

688 chromatography, and his-tagged octamers were isolated using cobalt-based immobilized metal

689 affinity chromatography Dynabeads magnetic particles. Octamers were incubated with magnetic

690 beads for $10 \mathrm{~min}$ at $4^{\circ} \mathrm{C}$ on rotator, followed by two $1 \mathrm{ml}$ washes $\left(50 \mathrm{mM} \mathrm{Na} \mathrm{PO}_{4} \mathrm{pH} 7.5,2 \mathrm{M}\right.$

$691 \mathrm{NaCl}, 10 \mathrm{mM}$ imidazole), and eluted with $50 \mathrm{ul}$ of elution buffer (50 mM Na $\mathrm{PO}_{4} \mathrm{pH}$ 7.5, $2 \mathrm{M}$

$692 \mathrm{NaCl}, 250 \mathrm{mM}$ imidazole, $1 \mathrm{mM}$ EDTA, $1 \mathrm{mM}$ DTT), the elution step was repeated 6 times,

693 fractions were characterized spectroscopically, pooled, diluted with 1 volume of octamer storage

694 buffer, and stored in $-20^{\circ} \mathrm{C}$.

695 Asymmetrical trans-bivalent H3K4me3-K27me3 octamers were prepared the same way as

696 symmetrical octamers with the following differences. Histones H2A, H2B, H4 and asymmetric

697 disulfide linked histones H3K4me3 - H3K27me3 were mixed 1.2 : 1.2 : 1 : 0.5 ratio. Remaining

698 steps were done as previously described but no reducing agents were used until octamer particles

699 were formed.

700 All other octamers were obtained from EpiCypher, Inc. 
Nucleosome reconstitution

703 DNA barcodes were constructed based on 601 nucleosome positioning sequence ${ }^{97}$. One or both

704 ends of 601 Widom sequence were substituted with 24 bp "barcode” sequence. Each barcode

705 sequence is comprised of two 11 bp sequences absent in human and mouse genome, and constant

706 2bp linker DNA is added on a free end of the 601 nucleosome positioning sequence.

707 Nucleosomes were reconstituted as previously described ${ }^{46}$. Briefly, 10-100 pmol DNA and

708 histone octamers were mixed in $1: 1$ ratio, at a final concentration $>1 \mu \mathrm{M}$, and dialyzed in

709 dialysis buttons (Hampton Research) against a non-linear gradient of sodium chloride $2 \mathrm{M} \mathrm{NaCl}$

$710 \rightarrow 0.2 \mathrm{M} \mathrm{NaCl}$ in a buffer containing $20 \mathrm{mM}$ Tris-HCl pH 7.5, $1 \mathrm{mM}$ EDTA, $10 \mathrm{mM}$

711 2-mercaptoethanol over the course of 12-16 hours ${ }^{84}$. Afterwards nucleosomes were recovered,

712 diluted with 1 volume of 2x storage buffer (20 mM Na•Cacodylate $\mathrm{pH}$ 7.5, 10\% v/v glycerol,

7131 mM EDTA, 1x RL Protease Inhibitor Cocktail [1 mM PMSF, 1 mM ABESF, $0.8 \mu \mathrm{M}$

714 aprotinin, $20 \mu \mathrm{M}$ leupeptin, $15 \mu \mathrm{M}$ pepstatin A, $40 \mu \mathrm{M}$ bestatin, $15 \mu \mathrm{M}$ E-64]), and stored at -

$71520^{\circ} \mathrm{C}$. Nucleosome concentration was measured by densitometry of 2\% agarose gels, 1x TBE (89

$716 \mathrm{mM}$ tris-base, $89 \mathrm{mM}$ boric acid, 2 mM EDTA) run for 30 minutes in 5V/cm electrical field

717 gradient, followed by staining with 1x SYBR Gold (Invitrogen) for $>30$ minutes. Prior to

718 electrophoresis, nucleosomes were disassembled with $2 \mathrm{M} \mathrm{NaCl}$, roughly 1 pmol of nucleosomes

719 were loaded per well and measured in triplicate against known quantity of free DNA of the same

720 size. For use as ICeChIP standards, the semi-synthetic nucleosomes were diluted to $1 \mathrm{nM}$

721 concentration using long-term storage buffer (10 mM Na•Cacodylate pH 7.5, $100 \mathrm{mM} \mathrm{NaCl,}$

$72250 \%$ Glycerol, 1 mM EDTA, 1x RL Protease Inhibitor Cocktail, 100 g/mL BSA(NEB)) and

723 stored at $-20^{\circ} \mathrm{C}$. 
726 ICeChIP has been done as previously described ${ }^{46,54}$. Briefly, $10^{7}-10^{8}$ plate adherent cells were

727 released using Accutase (Millipore), quenched with complete medium and collected (500 rcf,

7285 min., $4^{\circ} \mathrm{C}$ ). Subsequent steps have been done on ice, cells after each wash were collected by

729 centrifugation (500 rcf, 5 min., $4^{\circ} \mathrm{C}$ ). Cells were washed twice with $10 \mathrm{ml} \mathrm{PBS}$, twice with $5 \mathrm{ml}$

730 buffer $\mathrm{N}$ (15 mM Tris pH 7.5, $15 \mathrm{mM} \mathrm{NaCl,} 60 \mathrm{mM} \mathrm{KCl,} \mathrm{8.5 \%} \mathrm{(w/v)} \mathrm{Sucrose,} 5$ mM MgCl 2,1

731 mM CaCl 21 mM DTT, 1x RL Protease Inhibitor Cocktail). Cells’ membranes was lysed by

732 adding 1 volume of the 2x Lysis Buffer (Buffer N supplemented with 0.6\% NP-40 substitute

733 (Sigma)) to the single cell suspension resuspended in 2 PCVs (packed cell volumes) of Buffer N.

734 After 10 minutes incubation on ice, nuclei were collected by centrifugation and resuspended in at

735 least 6 PNV (packed nuclei volumes) of buffer N. Subsequently, nuclei were layered over $7.5 \mathrm{ml}$

736 Sucrose Cushion N (15 mM Tris pH 7.5, 15 mM NaCl, 60 mM KCl, 30\% (w/v) Sucrose, 5 mM

$737 \mathrm{MgCl}_{2}, 1 \mathrm{mM} \mathrm{CaCl} 21 \mathrm{mM}$ DTT, 1x RL Protease Inhibitor Cocktail, $50 \mu \mathrm{g} / \mathrm{mL}$ BSA(NEB)) in a

$73850 \mathrm{ml}$ centrifuge tube. Nuclei were spun through the sucrose cushion in swinging bucket rotor at

739500 rcf for 12 min., $4^{\circ} \mathrm{C}$. Nuclei were resuspended in 2 PNVs of buffer N, total nuclei acid

740 content was measured spectroscopically at $260 \mathrm{~nm}$ by Nanodrop (Thermo Scientific)

$741 \quad\left(1 \mathrm{~A}_{260}=50 \mathrm{ng} / \mu \mathrm{l}\right)$, prior to measurement, DNA was stripped from chromatin by adding $18 \mu \mathrm{l}-$

$74298 \mu \mathrm{l}$ of $2 \mathrm{M} \mathrm{NaCl}$ and DNA was fragmented by vortexing and water bath sonication. The

743 quality and quantity of nuclei was measured using a hemocytometer. The apparent concentration

744 of chromatin was adjusted to $1 \mu \mathrm{g} / \mu \mathrm{l}$ with Buffer $\mathrm{N}$. The following semi-synthetic standards

745 were then spiked in: symmetrical H3K4me3, H3K9me3, H3K27me3, H3K36me3, H3K79me2,

746 H3K4me3-K27me3 cis-bivalent, asymmetrical H3K4me3, H3K4me3-K27me3 trans-bivalent.

747 To fragment the DNA, we aliquoted $100 \mu \mathrm{g}$ of chromatin and added 1 Worthington unit of 
Micrococcal nuclease (Worthington) per $4.785 \mu \mathrm{g}$ of chromatin (measured at 260nm,

$\left.7491 \mathrm{~A}_{260}=50 \mathrm{ng} / \mu \mathrm{l}\right)$ and incubated at $37^{\circ} \mathrm{C}$ for 12 minutes. Digestion was stopped by adding

750 1/10 volume of 11x MNase stop buffer (110 mM EGTA, 110 mM EDTA pH 8.0). Subsequently,

751 nuclei were lysed by slowly adding $5 \mathrm{M} \mathrm{NaCl}$ while mixing on a vortex (lowest setting) to the

752 final concentration of $600 \mathrm{mM} \mathrm{NaCl}$. Insoluble material has been spun down at $18000 \mathrm{rcf}, 1 \mathrm{~min}$., $753 \quad 4^{\circ} \mathrm{C}$.

754 Hydroxyapatite (HAP) chromatography has been done as described previously ${ }^{46}$. Briefly, 66 mg 755 of HAP resin (Bio-Rad Macro-Prep ${ }^{\circledR}$ Ceramic Hydroxyapatite Type I $20 \mu \mathrm{m}$ ) was rehydrated 756 with $200 \mu \mathrm{l}$ of HAP buffer $1\left(3.42 \mathrm{mM} \mathrm{Na}_{2} \mathrm{HPO}_{4}\right.$ and $1.58 \mathrm{mM} \mathrm{NaH}_{2} \mathrm{PO}_{4}$ final pH 7.2, $600 \mathrm{mM}$ $757 \mathrm{NaCl}, 1 \mathrm{mM}$ EDTA, $200 \mu \mathrm{M}$ PMSF). Subsequently, $100 \mu$ g of digested soluble chromatin was 758 added to the rehydrated resin and incubated for 10 minutes at $4^{\circ} \mathrm{C}$ on a rotator. Afterwards, resin 759 slurry was transferred to the centrifugal filter unit (Millipore Ultrafree MC-HV Centrifugal Filter $760 \quad 0.45 \mu \mathrm{m})$. Resin was washed 4 times with $200 \mu \mathrm{l}$ of HAP buffer 1, 4 times with $200 \mu \mathrm{l}$ of HAP 761 buffer $2\left(3.42 \mathrm{mM} \mathrm{Na}_{2} \mathrm{HPO}_{4}\right.$ and $1.58 \mathrm{mM} \mathrm{NaH}_{2} \mathrm{PO}_{4}$ final pH 7.2, $100 \mathrm{mM} \mathrm{NaCl,} 1 \mathrm{mM}$ EDTA, $762200 \mu \mathrm{M}$ PMSF), and eluted 3 times with $50 \mu$ HAP elution buffer (342 mM Na $2 \mathrm{HPO}_{4}$ and 158 $763 \mathrm{mM} \mathrm{NaH}_{2} \mathrm{PO}_{4}$ final pH 7.2, $100 \mathrm{mM} \mathrm{NaCl}, 1 \mathrm{mM}$ EDTA, $200 \mu \mathrm{M}$ PMSF), each wash/elution 764 step was accompanied by centrifugation step (600 rcf, 30 sec., $4^{\circ} \mathrm{C}$ ). Concentration of the 765 chromatin was evaluated spectroscopically by Nanodrop (Thermo Scientific) $\left(1 \mathrm{~A}_{260}=50 \mathrm{ng} / \mathrm{\mu l}\right)$. 766 Apparent concentration of the chromatin was adjusted to $20 \mathrm{ng} / \mu \mathrm{l}$ with ChIP buffer 1 with BSA 767 (25 mM Tris pH 7.5, 5 mM MgCl 2,100 mM KCl, 10\% (v/v) glycerol, 0.1\% (v/v) NP-40 768 substitute, $100 \mu \mathrm{g} / \mathrm{ml}$ BSA(NEB)). 
771 ICeChIP was performed as previously described ${ }^{46}$ with following modifications: $\alpha$-H3K4me3

772 ChIP- $5 \mu$ g chromatin, $2 \mu \mathrm{g}$ 304M3B-1xHRV3C ${ }^{53}$, 40 $\mu$ l Streptavidin M-280 Dynabeads

773 (Invitrogen). $\alpha$-H3K9me3 ChIP- $3 \mu$ g chromatin, $0.5 \mu$ g 309M3B ${ }^{53}$, $10 \mu$ l Streptavidin M-280

774 Dynabeads (Invitrogen). $\alpha$-H3K27me3 ChIP - $0.8 \mu$ g chromatin, $0.6 \mu$ g CST C36B11 lot 8, $5 \mu \mathrm{l}$

775 Protein G Dynabeads (Invitrogen). Aforementioned volumes of magnetic beads were washed

776 twice with $200 \mu \mathrm{l}$ ChIP buffer 1 with BSA. Antibodies were resuspended in $100 \mu$ of ChIP

777 buffer 1 with BSA; subsequently, magnetic beads were collected using magnetic rack,

778 supernatant was removed, and magnetic beads were resuspended with the antibody solution and

779 incubated for at least $1 \mathrm{hr}, 4^{\circ} \mathrm{C}$, on a rotator. Afterwards unbound antibody was washed away

780 with two $200 \mu \mathrm{l}$ washes of ChIP buffer 1 with BSA. Streptavidin beads were additionally washed

781 twice with $200 \mu \mathrm{l}$ of ChIP buffer 1 with BSA supplemented with $5 \mu \mathrm{M}$ biotin for $10 \mathrm{~min}$, at $4^{\circ} \mathrm{C}$,

782 on a rotator for each wash, followed by wash with $200 \mu$ l ChIP buffer 1 with BSA. Supernatant

783 was removed on a magnetic rack and specific amount of chromatin, mentioned at the beginning

784 of this chapter, was used to resuspend the magnetic beads. Chromatin was incubated with

785 antibody-beads conjugates for $10-15$ minutes, at $4^{\circ} \mathrm{C}$, on a rotator.

786 Subsequently, magnetic beads were washed two times with $200 \mu$ l ChIP buffer 2 (25 mM Tris

$787 \mathrm{pH}$ 7.5, 5 mM MgCl $2,300 \mathrm{mM} \mathrm{KCl,} \mathrm{10 \%} \mathrm{(v/v)} \mathrm{glycerol,} \mathrm{0.1 \%} \mathrm{(v/v)} \mathrm{NP-40} \mathrm{substitute,} 100 \mu \mathrm{g} / \mathrm{ml}$

788 BSA(NEB)), and one time with $200 \mu$ l ChIP buffer 3 (10 mM Tris pH 7.5, $250 \mathrm{mM} \mathrm{LiCl,} 1 \mathrm{mM}$

789 EDTA, 0.5\% Na•Deoxycholate, 0.5\%(v/v) NP-40 substitute, $100 \mu \mathrm{g} / \mathrm{ml}$ BSA(NEB)), 10

790 minutes, at $4^{\circ} \mathrm{C}$, on a rotator with tube change after each wash. These washes were followed by

791 quick $200 \mu \mathrm{l}$ ChIP buffer 1 (without BSA) wash, and 200 $\mu \mathrm{l}$ TE wash (10 mM Tris-HCl pH 8.0,

$7921 \mathrm{mM}$ EDTA). Chromatin was released from the resin using $50 \mu$ l ChIP elution buffer (50 mM

793 Tris pH 7.5, $1 \mathrm{mM}$ EDTA, 1\% (w/v) SDS) at $55^{\circ} \mathrm{C}$, for 5 minutes. Elution was supplemented 
794 with $200 \mathrm{mM} \mathrm{NaCl}, 10 \mathrm{mM}$ EDTA, $10 \mu \mathrm{g}$ of Proteinase $\mathrm{K}$ (Roche) and incubated at $55^{\circ} \mathrm{C}$ for 2

795 hours. DNA was isolated using 3 volumes of Serapure HD (1 mg/ml of $1 \mu \mathrm{m}$, hydrophobic,

796 carboxylated, Sera-Mag SpeedBeads (GE 65152105050250), 20\% PEG-8000, 2.5 M NaCl,

$79710 \mathrm{mM}$ Tris pH 7.5, 1 mM EDTA, 0.05\% Tween-20, filter sterilized prior to addition of

798 magnetic beads), incubated for 5 minutes at room temperature, collected with magnetic rack and

799 washed twice with $>200 \mu$ l of $75 \%$ ethanol, on a magnetic rack without disturbing the magnetic

800 beads. Subsequently, ethanol was carefully removed, and DNA was eluted by resuspending

801 beads in $50 \mu \mathrm{l}$ of TE buffer, magnetic beads were collected using magnetic rack and supernatant

802 was moved to a new tube. In order to limit DNA loss, all operations have been performed using

$803250 \mu \mathrm{l}$ siliconized tubes.

805 reICeChIP

806 reICeChIP was performed in the same manner as described above with following changes. For

807 the primary IP we have used $5 \mu \mathrm{g}$ of HAP purified chromatin, $2 \mu \mathrm{g}$ 304M3B-1xHRV3C - HRV

$8083 \mathrm{C}$ cleavable, biotinylated, $\alpha \mathrm{H} 3 \mathrm{~K} 4 \mathrm{me} 3 \mathrm{Fab}(\mathrm{PDB}: 4 \mathrm{YHZ})^{53}$, immobilized on $40 \mu \mathrm{l}$ Streptavidin

809 M-280 Dynabeads (Invitrogen). After 10 minutes incubation of chromatin with antibody-resin

810 conjugate, resin was washed three times with $200 \mu$ l ChIP buffer 1 with $100 \mu \mathrm{g} / \mathrm{ml}$ BSA, each

811 wash consisted of 10 minutes incubation at $4^{\circ} \mathrm{C}$, on a rotator, followed by tube change.

812 Subsequently, resin was briefly washed with $200 \mu \mathrm{l} \mathrm{ChIP} \mathrm{buffer} 1$ with $100 \mu \mathrm{g} / \mathrm{ml} \mathrm{BSA}$, and

813 chromatin was released from the resin with $20 \mu \mathrm{l}$ of ChIP buffer 1 supplemented with $100 \mu \mathrm{g} / \mathrm{ml}$

814 BSA and $4 \mu$ g HRV3C incubated (GE Healthcare) on ice for 60 minutes, elution step was

815 repeated one more time and both elutions were combined. HRV 3C endoprotease efficiently

816 cleaves at its target sites at $4^{\circ} \mathrm{C}^{55}$ and has a wide range of chemical tolerance ${ }^{98}$, but it highly- 
817 specific for its cognate cleavage sequence ${ }^{99}$ permitting facile use in ChIP under conditions which

818 preserve nucleosomes. Primary elution was added to $0.6 \mu \mathrm{g}$ CST C36B11, $\alpha \mathrm{H} 3 \mathrm{~K} 27 \mathrm{me} 3 \mathrm{mAb}$,

819 immobilized on $5 \mu$ l of Protein G Dynabeads(Invitrogen) for 10 minutes, at $4^{\circ} \mathrm{C}$, on a rotator.

820 Subsequently, magnetic beads were washed two times with $200 \mu$ l ChIP buffer 2, and one time

821 with $200 \mu \mathrm{l}$ ChIP buffer 3, 10 minutes, at $4^{\circ} \mathrm{C}$, on a rotator, with tube change after each wash.

822 These washes were followed by quick wash with $200 \mu$ l ChIP buffer 1 (without BSA).

823 Chromatin was released from the resin by 5 minutes incubation with $50 \mu$ l ChIP elution buffer, at

$82455^{\circ} \mathrm{C}$. Chromatin was Proteinase K digested, and DNA was purified as described in ICeChIP -

825 immunoprecipitation chapter.

826

827 Design, expression, and purification of 304M3B-1xHRV3C

828 304M3B-1xHRV3C Fab is based on previously described Fab 304M3B(PDB:4YHZ) ${ }^{53}$. The

829 gene encoding the Fab was modified to contain HRV3C cleavage site at the C-terminus of the

830 heavy chain. To that end, we inserted SSSLEVLFQGP (AGC AGC AGC CTT GAA GTC CTC

831 TTT CAG GGA CCC) sequence just after the position T229 of heavy chain (numbered as in

832 PDB:4YHZ) and before biotinylation acceptor peptide (GLNDIFEAQKIEWHE) ${ }^{100}$. The Fab was

833 expressed in the 55244 strain of E.coli in the TBG media (Terrific Broth (FisherBrand), 0.8\%

834 (v/v) glycerol) with $100 \mu \mathrm{g} / \mathrm{ml}$ carbenicilin, grown for 24 hours, at $30^{\circ} \mathrm{C}, 200 \mathrm{rpm}$ in the

835 Fernbach non-baffled flasks, with constricted airflow. Fab was purified using Protein G-A1 ${ }^{101}$

836 affinity chromatography, followed by cation-exchange chromatography (Resource S, GE

837 Healthcare). Purified Fab was in vitro biotinylated using BirA biotin ligase. 
840 Each sequencing library was made using 10 ng of DNA. Illumina sequencing libraries were

841 made with NEBNext Ultra II DNA Library Prep for Illumina (NEB), according to the

842 manufacturer protocol. DNA libraries were amplified using 8 PCR amplification cycles (C1000,

843 Bio-Rad). Cluster generation and sequencing was performed using the standard Illumina

844 protocols for Illumina HiSeq 4000 by the University of Chicago Functional Genomics Core

845 facility. Data analysis was performed as previously described ${ }^{46}$. Briefly, reference genome was

846 modified to contain sequences of semi-synthetic nucleosome barcodes. Reads were mapped to

847 GRCm38/mm10+barcodes reference genome, using Bowtie $2^{102}$, end-to-end, sensitive preset.

848 Subsequently, SAM files were filtered to reject unmapped and unpaired reads, as well as

849 fragments with length $>200 \mathrm{bp}$ and Phred quality score $<2$. Paired reads were merged into

850 single interval of the fragment. BEDTools ${ }^{103}$ were used to calculate bedgraphs of the genome

851 coverage. IP and input bedgraphs of genome coverage were subsequently merged into multiple

852 entry interval file of genome coverage. Number of DNA fragments coming from semi-synthetic

853 nucleosome standards were counted for each barcode and IP efficiency was calculated for each

854 histone mark.

855

$$
\text { BarcodeIPenrichment }=\frac{\sum_{1}^{n} I P}{\sum_{1}^{n} \text { input }}
$$

856 where, $\mathrm{n}$ is the identity of the $\mathrm{n}$-th barcode assigned to the specific histone mark.

$$
H M D(\text { per } / b p)=\frac{\left(\frac{I P}{\text { input }}\right) * 100 \%}{\text { BarcodeIPenrichment }}
$$

858 where, IP and input refer to the depth of the genome coverage at any given position of IP and

859 input for specific histone mark. An IP efficiency can be interpreted as maximal yield of the IP for

860 a given histone mark, or 100\% HMD. However, there is a number of factors that can lead to 
861 apparent HMD values greater than 100\% including: uncertainty due to random sampling of

862 sequenced fragments, in that case standard deviation is approximately equal to square root of

863 sequencing depth, or off-target capture by antibody, where the off-target histone mark or

864 combination of histone marks have greater IP efficiency than the antibody intended target mark.

865 For all analyses, the HMD averaged over the $\mathrm{N}+1$ and $\mathrm{N}+2$ nucleosomes (taken to be 0 to

866 +400bp into the gene body) was employed as representative of the promoter - this captures the

867 most substantial H3K4me3 and H3K27me3 enrichment.

868 Genomic browser views were made using IGV. Heatmaps and gene ontology analysis was made

869 using Homer Software ${ }^{104}$. Further analysis and sectioning of data was conducted in R using the R

870 code provided in Data Availability. Plots were made using ggplot2 and Microsoft Excel. For the

871 bivalency tracks, in silico antibody off-specificity correction was performed as previously

872 described for H3K9me3 ${ }^{46}$. ICeChIP-qPCR was performed with previously described primers ${ }^{46}$.

874 Analysis of External Data

875 Bisulfite sequencing data was obtained from GEO series accession number GSE41923, dataset

876 accession numbers GSM1027571, GSM1027572, GSM1027573, and GSM1027574.

877 Methylation count files were obtained for each dataset and lifted to mm10. The average

878 methylation for each promoter was then calculated for the 0 to +400 bp region relative to the TSS

879 of Refseq promoters using BEDTools.

880 Bulk RNA-seq data was obtained from GEO series accession numbers GSE108832 and

881 GSE65697, dataset accession numbers GSM2913929, GSM2913930, GSM2913931,

882 GSM1603282, GSM1603283, GSM1603284, GSM1603285, GSM1603286, and GSM1603287. 
883 Pseudoalignment was conducted against the Refseq mm10 transcriptome using kallisto ${ }^{105}$ with

884 fragment length mean and standard deviation of 200 and 20, respectively, and 100 iterations.

885 Pseudoalignments were then loaded into R for differential expression analysis using sleuth ${ }^{106}$,

886 with correction for batch effects between primed mESCs and NPCs due to contribution to

887 principal components of the same. Differentially expressed genes were identified as $q \leq 0.05$.

888 Single-cell RNA-seq data was obtained from GEO series accession number GSE113417 and

889 aligned as above with kallisto.

891 KO cells was obtained from GEO series accession number GSE116603, dataset accession

892 numbers GSM3243624, GSM3243625, and GSM3243626. Peak files were obtained for all these

893 datasets lifted to mm10. Ezh2 peaks were identified as peaks lost in Ezh2 KO relative to WT

894 cells. Ezh1 peaks were identified as peaks lost in Ezh1 KO/Ezh2 KO relative to Ezh2 KO cells.

Set1A ChIP data was obtained from GEO series accession number GSE98988, dataset

896 accession numbers GSM2629676, GSM2629677, GSM2629678, and GSM2629691. FastQ files

897 were downloaded for the input and ChIP datasets for each replicate, then aligned to mm10 using

898 Bowtie2 in end-to-end mode with the sensitive preset. Peak calling was then conducted on the

899 alignments with MACS2 ${ }^{107}$, and consensus peaks for each replicate were identified.

Mll2 ChIP data was obtained from GEO series accession number GSE78708, dataset

901 accession number GSM2073022. Peaks were obtained and lifted to mm10.

902

903 Methyltransferase assays 
904 Enzymatic complexes were procured from Reaction Biology Corporation. Methyltransferase

905 reactions were done using following concentrations of the enzymatic complexes: $200 \mathrm{nM}$

906 hsMLL1(3745-3969), 200 nM hsMLL2(5319-5537), 400 nM hsMLL3(4689-4911), 200 nM

907 hsMLL4(2490-2715), 800 nM hsSet1A(1418-1707), 800 nM hsSet1B(1629-1923), in a complex

908 with hsWDR5(22-334), haRbBP5(1-538), hsAsh2L(2-534), 2x(hsDPY-30(1-99)), supplemented

909 with 4\%(v/v) RBC MLL enhancer (Reaction Biology Corp); 800 nM hsEzh1(2-747), 120 nM

910 hsEzh2(2-746), in a complex with hsAEBP2(2-517), hsEED(2-441), hsRbAp48(2-425) and

911 hsSUZ12(2-739) supplemented with 3.6mM hsJarid2(119-574) provided by Dr. Peter Lewis’s

912 laboratory. $30 \mathrm{ng} / \mu \mathrm{l}$ of semi-synthetic nucleosome substrate, $10 \mu \mathrm{M}\left[{ }^{3} \mathrm{H}\right]-\mathrm{SAM}(50-80 \mathrm{Ci} / \mathrm{mmol}$,

913 Perkin Elmer Health Sciences), and enzymatic complexes were mixed in the Reaction Buffer (50

$914 \mathrm{mM}$ Tris pH 8.0, $91 \mathrm{mM} \mathrm{NaCl,} 5 \mathrm{mM} \mathrm{MgCl}$, 1 mM DTT, 10\% glycerol, $1 \mathrm{mM} \mathrm{PMSF)} \mathrm{and}$

915 incubated at $30^{\circ} \mathrm{C}$. At designated time points, $4 \mu \mathrm{l}$ of reactions were spotted on P81 Ion

916 Exchange Cellulose Chromatography Paper (Reaction Biology Corp). Spotted paper was washed

9174 times with $250 \mathrm{ml}$ of $50 \mathrm{mM} \mathrm{NaHCO}_{3} \mathrm{pH}$ 9.0, for 5 minutes on a platform shaker, briefly

918 washed with acetone, air-dried and immersed in scintillation fluid. ${ }^{3} \mathrm{H}$ decay rate was measured

919 by scintillation counter (LS 6000IC, Beckman).

920

921 Data and Software Availability

922 ICeChIP-seq data generated for this study has been deposited at the Gene Expression Omnibus

923 (GEO) under accession numbers GSE108747 and GSE183155. R markdown file for analysis and

924 sectioning of datasets is provided at https://www.github.com/shah-rohan/bivalency/. 


\section{Supplementary References}

1107 81. Young, N. L. et al. High Throughput Characterization of Combinatorial Histone Codes.

1108 Mol. Cell. Proteomics MCP 8, 2266-2284 (2009).

1109 82. Lavarone, E., Barbieri, C. M. \& Pasini, D. Dissecting the role of H3K27 acetylation and 1110 methylation in PRC2 mediated control of cellular identity. Nat. Commun. 10, 1679 (2019).

1111 83. Radman-Livaja, M. \& Rando, O. J. Nucleosome positioning: how is it established, and 1112 why does it matter? Dev. Biol. 339, 258-266 (2010).

1113 84. Ruthenburg, A. J. et al. Recognition of a mononucleosomal histone modification pattern 1114 by BPTF via multivalent interactions. Cell 145, 692-706 (2011).

1115 85. Rothbart, S. B. et al. Multivalent histone engagement by the linked tandem Tudor and 1116 PHD domains of UHRF1 is required for the epigenetic inheritance of DNA methylation. Genes 1117 Dev. 27, 1288-1298 (2013).

1118 86. Savitsky, P. et al. Multivalent Histone and DNA Engagement by a PHD/BRD/PWWP 1119 Triple Reader Cassette Recruits ZMYND8 to K14ac-Rich Chromatin. Cell Rep. 17, 2724-2737 1120 (2016).

1121 87. Yun, M., Wu, J., Workman, J. L. \& Li, B. Readers of histone modifications. Cell Res. 21, $1122 \quad 564-578(2011)$

1123 88. Amemiya, H. M., Kundaje, A. \& Boyle, A. P. The ENCODE Blacklist: Identification of 1124 Problematic Regions of the Genome. Sci. Rep. 9, 9354 (2019).

1125 89. Margueron, R. et al. Role of the polycomb protein EED in the propagation of repressive 1126 histone marks. Nature 461, 762-767 (2009). 
1127 90. Yuan, W. et al. Dense Chromatin Activates Polycomb Repressive Complex 2 to Regulate

1128 H3 Lysine 27 Methylation. Science 337, 971-975 (2012).

1129 91. Hooper, M., Hardy, K., Handyside, A., Hunter, S. \& Monk, M. HPRT-deficient (Lesch-

1130 Nyhan) mouse embryos derived from germline colonization by cultured cells. Nature 326, 292-

1131295 (1987).

1132 92. Conti, L. et al. Niche-Independent Symmetrical Self-Renewal of a Mammalian Tissue

1133 Stem Cell. PLOS Biol. 3, e283 (2005).

1134 93. Abranches, E. et al. Neural Differentiation of Embryonic Stem Cells In Vitro: A Road

1135 Map to Neurogenesis in the Embryo. PLOS ONE 4, e6286 (2009).

1136 94. Chen, Z., Grzybowski, A. T. \& Ruthenburg, A. J. Traceless semisynthesis of a set of

1137 histone 3 species bearing specific lysine methylation marks. Chembiochem Eur. J. Chem. Biol.

1138 15, 2071-2075 (2014).

1139 95. Luger, K., Rechsteiner, T. J. \& Richmond, T. J. Preparation of nucleosome core particle

1140 from recombinant histones. in Methods in Enzymology vol. 304 3-19 (Academic Press, 1999).

1141 96. Dyer, P. N. et al. Reconstitution of nucleosome core particles from recombinant histones 1142 and DNA. Methods Enzymol. 375, 23-44 (2004).

1143 97. Lowary, P. T. \& Widom, J. New DNA sequence rules for high affinity binding to histone

1144 octamer and sequence-directed nucleosome positioning. J. Mol. Biol. 276, 19-42 (1998).

1145 98. Ullah, R. et al. Activity of the Human Rhinovirus 3C Protease Studied in Various

1146 Buffers, Additives and Detergents Solutions for Recombinant Protein Production. PLOS ONE

1147 11, e0153436 (2016). 
1148 99. Cordingley, M. G., Callahan, P. L., Sardana, V. V., Garsky, V. M. \& Colonno, R. J.

1149 Substrate requirements of human rhinovirus 3C protease for peptide cleavage in vitro. J. Biol.

1150 Chem. 265, 9062-9065 (1990).

1151 100. Beckett, D., Kovaleva, E. \& Schatz, P. J. A minimal peptide substrate in biotin

1152 holoenzyme synthetase-catalyzed biotinylation. Protein Sci. Publ. Protein Soc. 8, 921-929

1153 (1999).

1154 101. Bailey, L. J. et al. Applications for an engineered Protein-G variant with a pH

1155 controllable affinity to antibody fragments. J. Immunol. Methods 415, 24-30 (2014).

1156 102. Langmead, B., Trapnell, C., Pop, M. \& Salzberg, S. L. Ultrafast and memory-efficient

1157 alignment of short DNA sequences to the human genome. Genome Biol. 10, R25 (2009).

1158 103. Quinlan, A. R. \& Hall, I. M. BEDTools: a flexible suite of utilities for comparing

1159 genomic features. Bioinforma. Oxf. Engl. 26, 841-842 (2010).

1160 104. Heinz, S. et al. Simple Combinations of Lineage-Determining Transcription Factors

1161 Prime cis-Regulatory Elements Required for Macrophage and B Cell Identities. Mol. Cell 38,

$1162 \quad 576-589$ (2010).

1163 105. Bray, N. L., Pimentel, H., Melsted, P. \& Pachter, L. Near-optimal probabilistic RNA-seq

1164 quantification. Nat. Biotechnol. 34, 525-527 (2016).

1165 106. Pimentel, H., Bray, N. L., Puente, S., Melsted, P. \& Pachter, L. Differential analysis of

1166 RNA-seq incorporating quantification uncertainty. Nat. Methods 14, 687-690 (2017).

1167 107. Zhang, Y. et al. Model-based Analysis of ChIP-Seq (MACS). Genome Biol. 9, R137

1168 (2008). 

available under aCC-BY 4.0 International license.

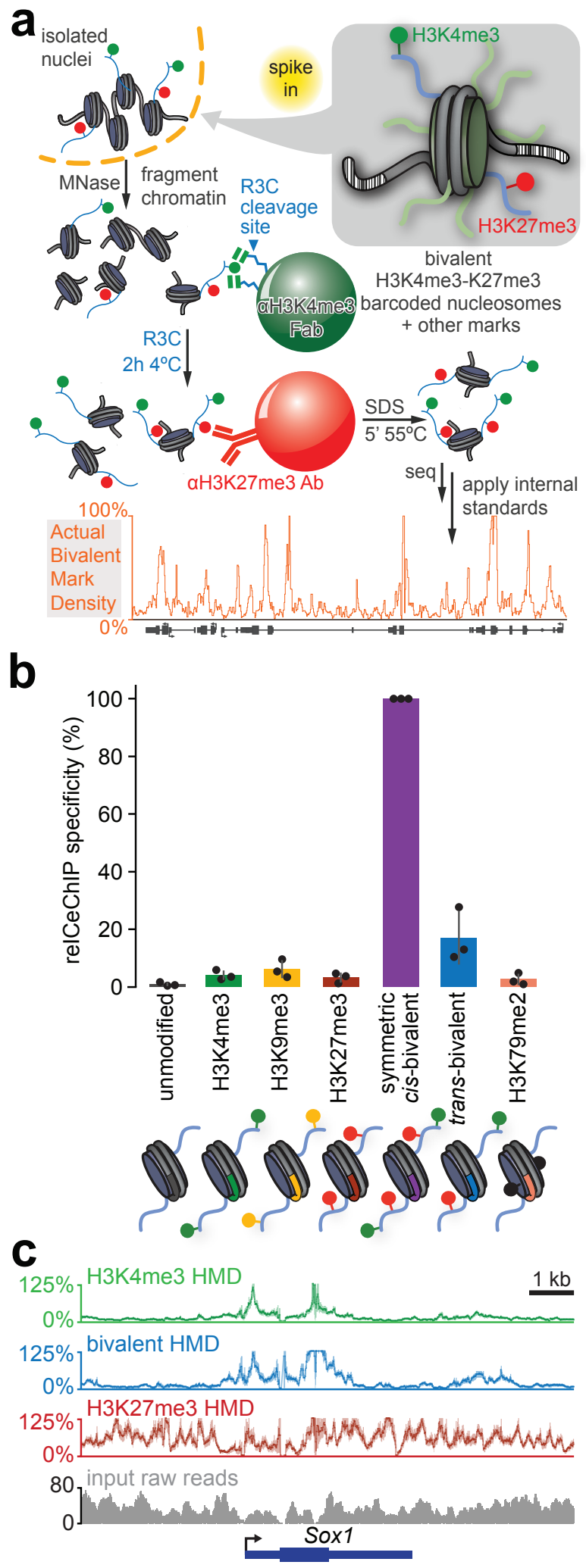

Fig. 1 | Workflow and evaluation of reICeChIP-seq. (a) Schematic of reICeChIP-seq. The recombinant $\alpha-\mathrm{H} 3 \mathrm{~K} 4 \mathrm{me} 3 \mathrm{Fab} 304 \mathrm{M} 3-\mathrm{B}$ achieves high affinity by "clasping" the histone tail between two Fab molecules ${ }^{53}$, a binding mode readily achieved by multiple copies of the Fab presented on a bead, but not by the Fab in solution. Thus, protease cleavage not only elutes nucleosomes from the beads but also likely from the Fab complex. (b) Enrichment of different barcoded nucleosomes in reICeChIP-seq ( $\mathrm{n}=3$ biological replicates). Error bars represent S.D. (c) Representative line plot showing histone modification density of H3K4me3, H3K27me3, and bivalency ICeChIP-seq presented with 95\% confidence intervals (lighter shade) and input read depth in naïve mESCs. Bivalency is calibrated to the trans-bivalency nucleosome standard and corrected for off-target H3K9me3 pulldown. 
bioRxiv preprint doi: https://doi.org/10.1101/2021.09.09.458948; this version posted September 10, 2021. The copyright holder for this preprint (which was not certified by peer review) is the author/funder, who has granted bioRxiv a license to display the preprint in perpetuity. It is made available under aCC-BY 4.0 International license.

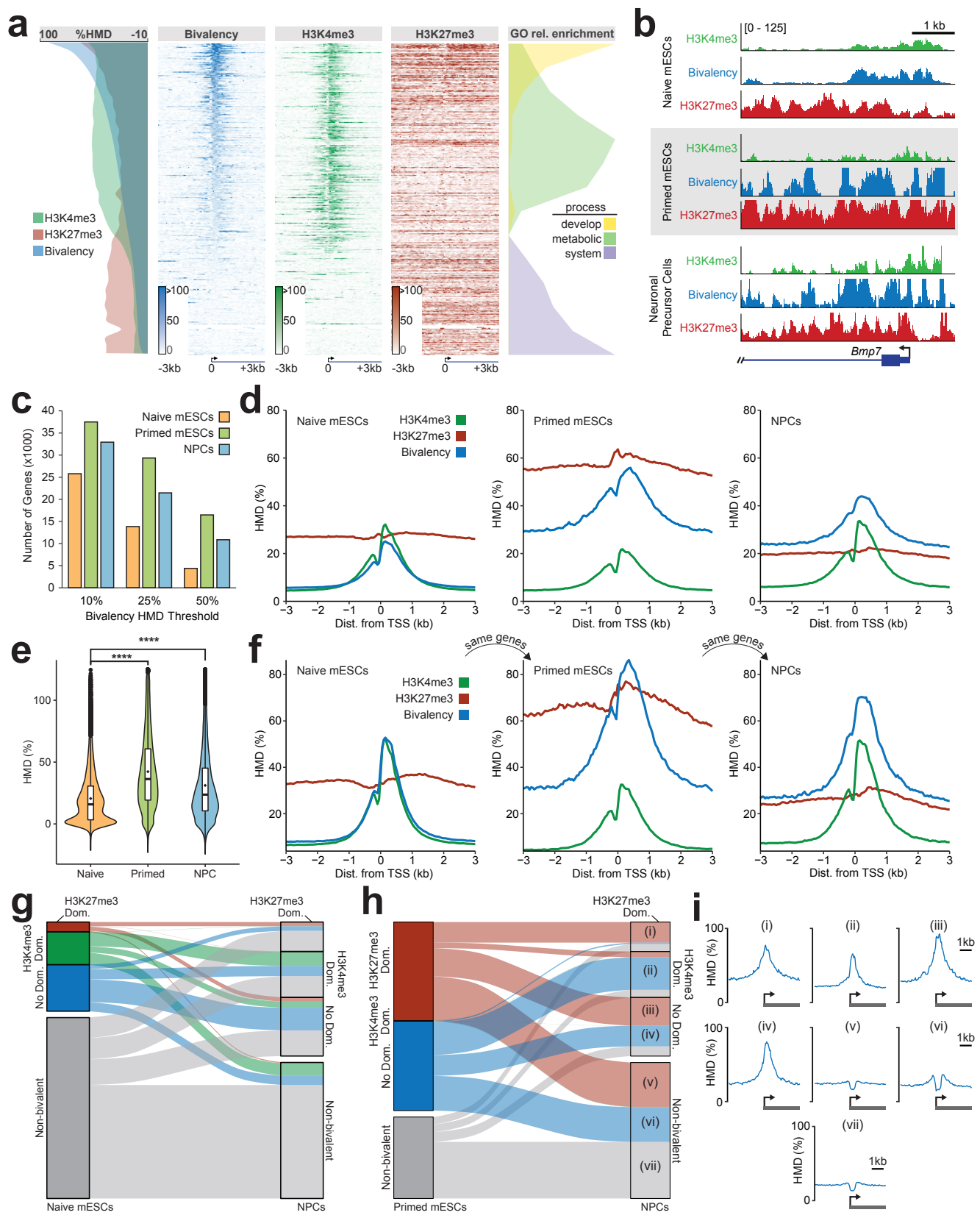

Fig. 2 | Bivalency is widespread and does not resolve over differentiation. (a) Bivalency, H3K4me3, and H3K27me3 at all Refseq promoters in naïve mESCs, with relative enrichment of GO terms. Genes are rank ordered by bivalency HMD at promoter, defined as the region from 0 to +400 bp relative to the TSS. (b) Representative locus view of $\mathrm{H} 3 \mathrm{~K} 4 \mathrm{me} 3, \mathrm{H} 3 \mathrm{~K} 27 \mathrm{me} 3$, and bivalency at promoters in naïve mESCs (top), primed mESCs (centre), and NPCs (bottom), presented on the same scale of 0-125\% HMD. (c) Number of promoters with bivalency HMDs above the given thresholds in each cell type out of a total of 42,622 Refseq promoters. (d) Metaprofiles of $\mathrm{H} 3 \mathrm{~K} 4 \mathrm{me} 3, \mathrm{H} 3 \mathrm{~K} 27 \mathrm{me} 3$, and bivalency at all promoters in naïve mESCs, primed mESCs, and NPCs. Heatmaps for primed mESCs and NPCs are presented in Extended Data Fig. 3b. (e) Distribution of bivalency HMDs at all Refseq promoters in three cell states, zoomed to below 125\% HMD. Overall, 99.5\% of naïve promoters, $87.3 \%$ of primed promoters, and 91.6\% of NPC promoters have an HMD below 100\%. Full plot in Extended Data Fig. 3a. (f) Metaprofiles of H3K4me3, H3K27me3, and bivalency at promoters identified as bivalent in naïve mESCs (25\% HMD threshold), tracked from naïve mESCs to primed mESCs to NPCs. Heatmaps for bivalency are presented in Extended Data Fig. 3f. (g-h) Alluvial plots of dominance and bivalency of genes from $(\mathrm{g})$ naïve mESCs to NPCs or $(\mathrm{h})$ primed mESCs to NPCs. Bivalency [ $>25 \% \mathrm{HMD}$ ] can be subcategorized into dominance classes by independent ICeChIP for the constituent marks, with H3K27me3 in excess (H3K27me3/H3K4me3 $\left.>e^{l}\right)$, H3K4me3 dominant (H3K27me3/H3K4me3 $<e^{-1}$ ), or intermediate ratios (no dominance). (i) Bivalency metaprofiles for gene subsets indicated in panel (h) from $-3 \mathrm{~kb}$ to $+3 \mathrm{~kb}$ relative to the TSS. $* * * * p<2.2 \times 10^{-16}$. 
bioRxiv preprint doi: https://doi.org/10.1101/2021.09.09.458948; this version posted September 10, 2021. The copyright holder for this preprint (which was not certified by peer review) is the author/funder, who has granted bioRxiv a license to display the preprint in perpetuity. It is made available under aCC-BY 4.0 International license.
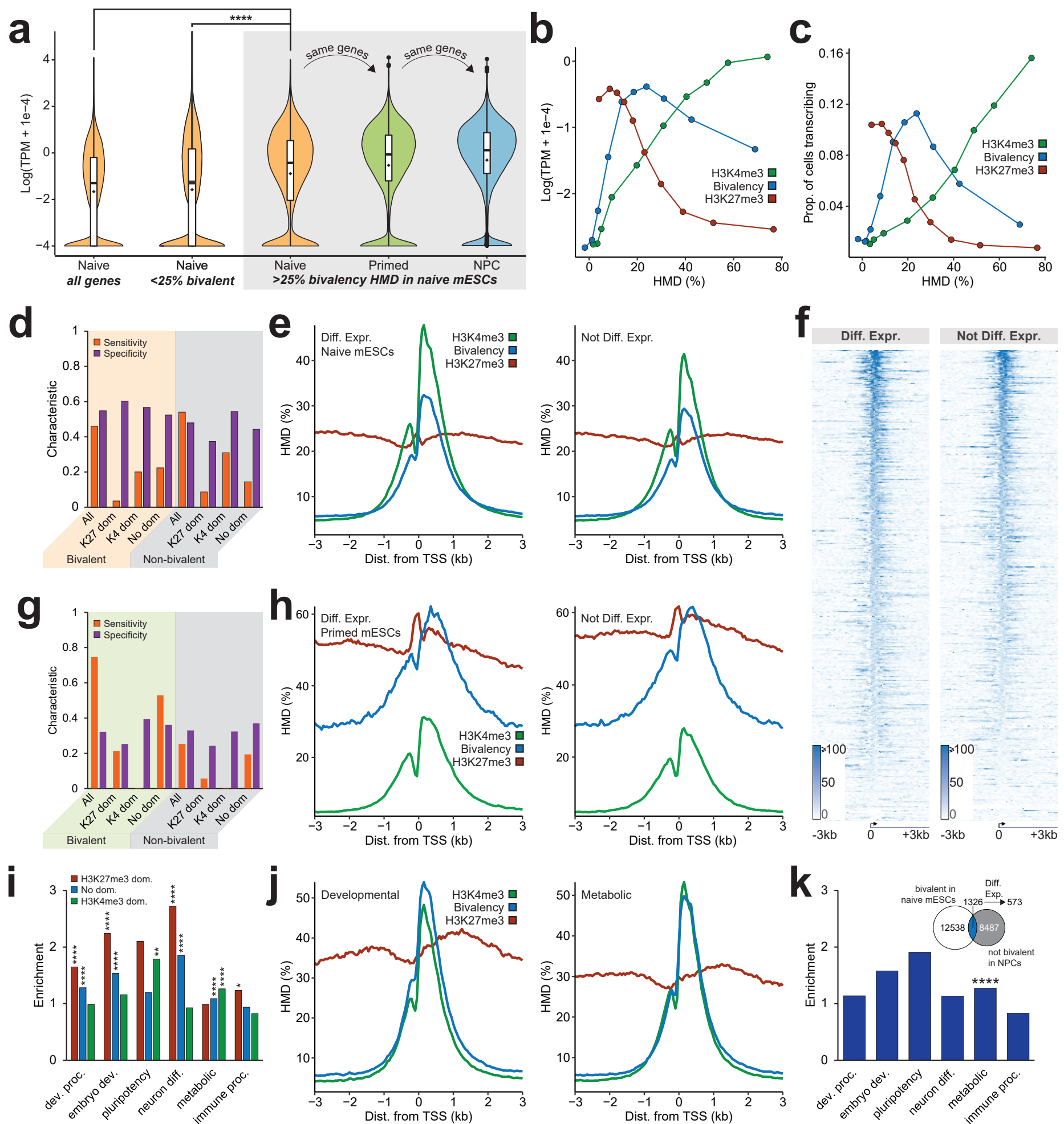

Fig. 3 | Bivalency is neither sensitive nor specific for poised nor developmental genes. (a) Violin plots of gene expression ${ }^{79}$ for all genes in naïve mESCs, non-bivalent genes ( $\left.<25 \% \mathrm{HMD}\right)$ in naïve $\mathrm{mESCs}$, and bivalent genes $(>25 \% \mathrm{HMD})$ tracked from naïve $\mathrm{mESCs}$ to the same genes in the indicated lineages. Significance computed by Welch's two-tailed $t$-test. (b) Gene expression vs. HMD for H3K4me3, H3K27me3, and bivalency (genes are binned into HMD deciles). (c) Proportion of actively transcribing cells by single-cell RNA-seq ${ }^{80}$ vs. HMD for H3K4me3, H3K27me3, and bivalency (genes are binned into HMD deciles). (d) Sensitivity and specificity (Supplementary Note 5) of bivalent and non-bivalent genes in naïve mESCs identifying differentially expressed genes (DEGs) from the naïve state to the NPC state. (e) Metaprofiles of H3K4me3, H3K27me3, and bivalency and (f) heatmaps of bivalency in naïve mESCs at DEGs and non-DEGs relative to NPCs. (g) Sensitivity and specificity of bivalent and non-bivalent genes in primed mESCs identifying DEGs from the primed state to the NPC state. (h) Metaprofiles of H3K4me3, H3K27me3, and bivalency in primed mESCs at DEGs 
bioRxiv preprint doi: https://doi.org/10.1101/2021.09.09.458948; this version posted September 10, 2021. The copyright holder for this preprint (which was not certified by peer review) is the author/funder, who has granted bioRxiv a license to display the preprint in perpetuity. It is made available under aCC-BY 4.0 International license.

and non-DEGs. (i) Gene ontology term enrichment of H3K27me3-dominant bivalent genes, H3K4me3-dominant bivalent genes, or bivalent genes with no clear dominance (q-value two-tailed Fisher hypergeometric test). (j) Metaprofiles of H3K4me3, H3K27me3, and bivalency in naïve mESCs at developmental and metabolic genes. (k) Gene ontology term enrichment of genes following the classic bivalency model: DEGs that lose bivalency from naïve mESCs $(>25 \%$ HMD) to NPCs $(<10 \%$ HMD). Significance computed by two-tailed Fisher hypergeometric test. $* q<0.05$. $* * q<0.01$. **** $p$ or $q<2.2 \times 10^{-16}$. 

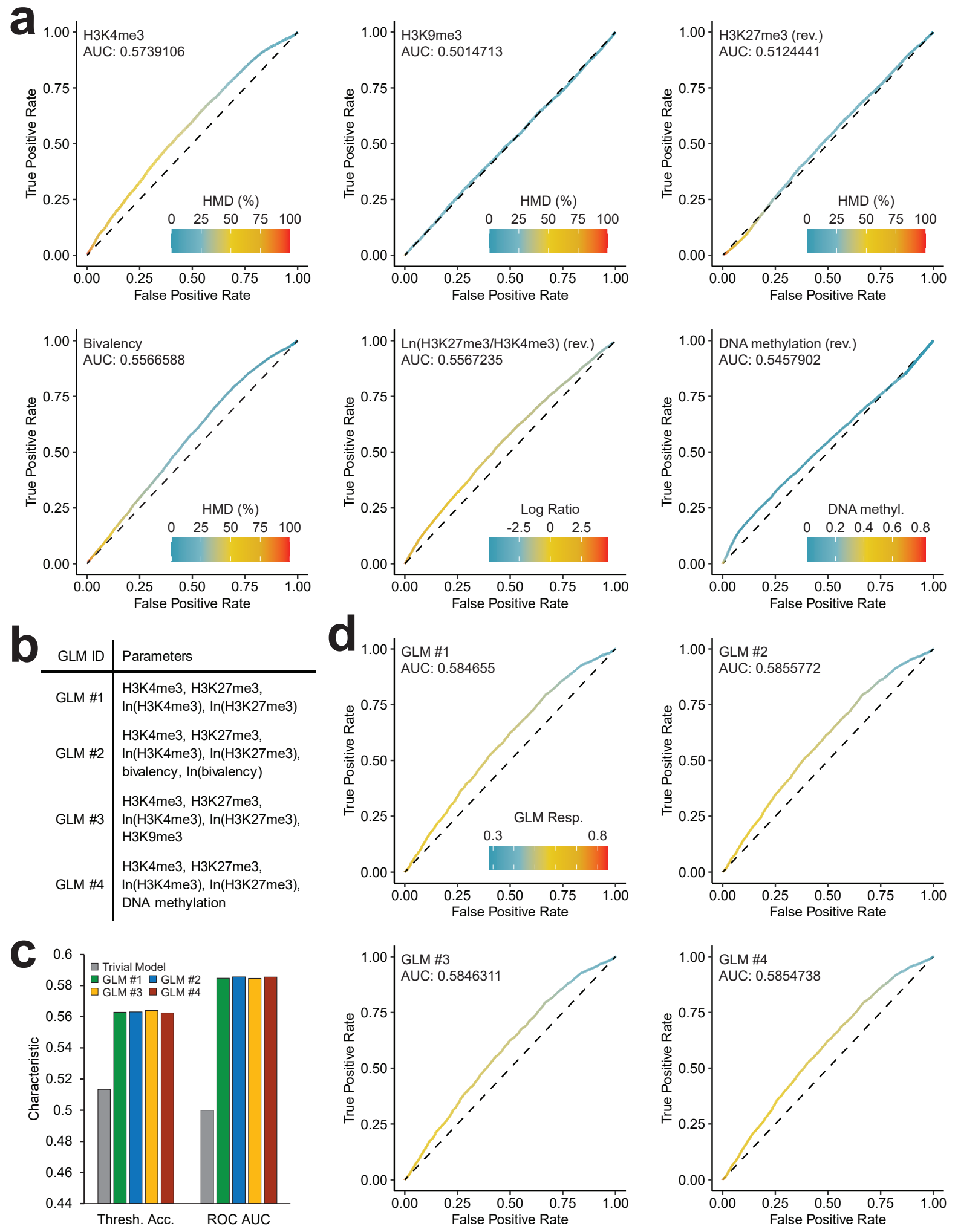

Fig. 4 | Bivalency does not provide appreciably more information than H3K4me3 and H3K27me3 alone for DEG prediciton. (a) Receiver operator characteristic (ROC) curves for identifying DEGs from naïve mESCs to NPCs by H3K4me3, H3K9me3, H3K27me3, bivalency, $\ln (\mathrm{H} 3 \mathrm{~K} 27 \mathrm{me} 3 / \mathrm{H} 3 \mathrm{~K} 4 \mathrm{me} 3)$, or DNA methylation in naïve mESCs. For each point, parameter value threshold used to compute true positive rate (TPR) and false positive rate (FPR) is indicated by the colour. Traits with thresholds identifying non-DEGs rather than DEGs are marked with "rev." (b) Legend for generalized linear models (GLMs) in panels c-d. (c) Accuracy of trivial model and GLMs by threshold accuracy (gene identified as DEG if logistic regression $>0.5$; left) and by ROC area under curve (right). (d) ROC curves for identifying DEGs from naïve mESCs to NPCs by different GLMs. For each point, logistic regression threshold value used to compute TPR and FPR is indicated by the colour. 
bioRxiv preprint doi: https://doi.org/10.1101/2021.09.09.458948; this version posted September 10, 2021. The copyright holder for this preprint (which was not certified by peer review) is the author/funder, who has granted bioRxiv a license to display the preprint in perpetuity. It is made available under aCC-BY 4.0 International license.
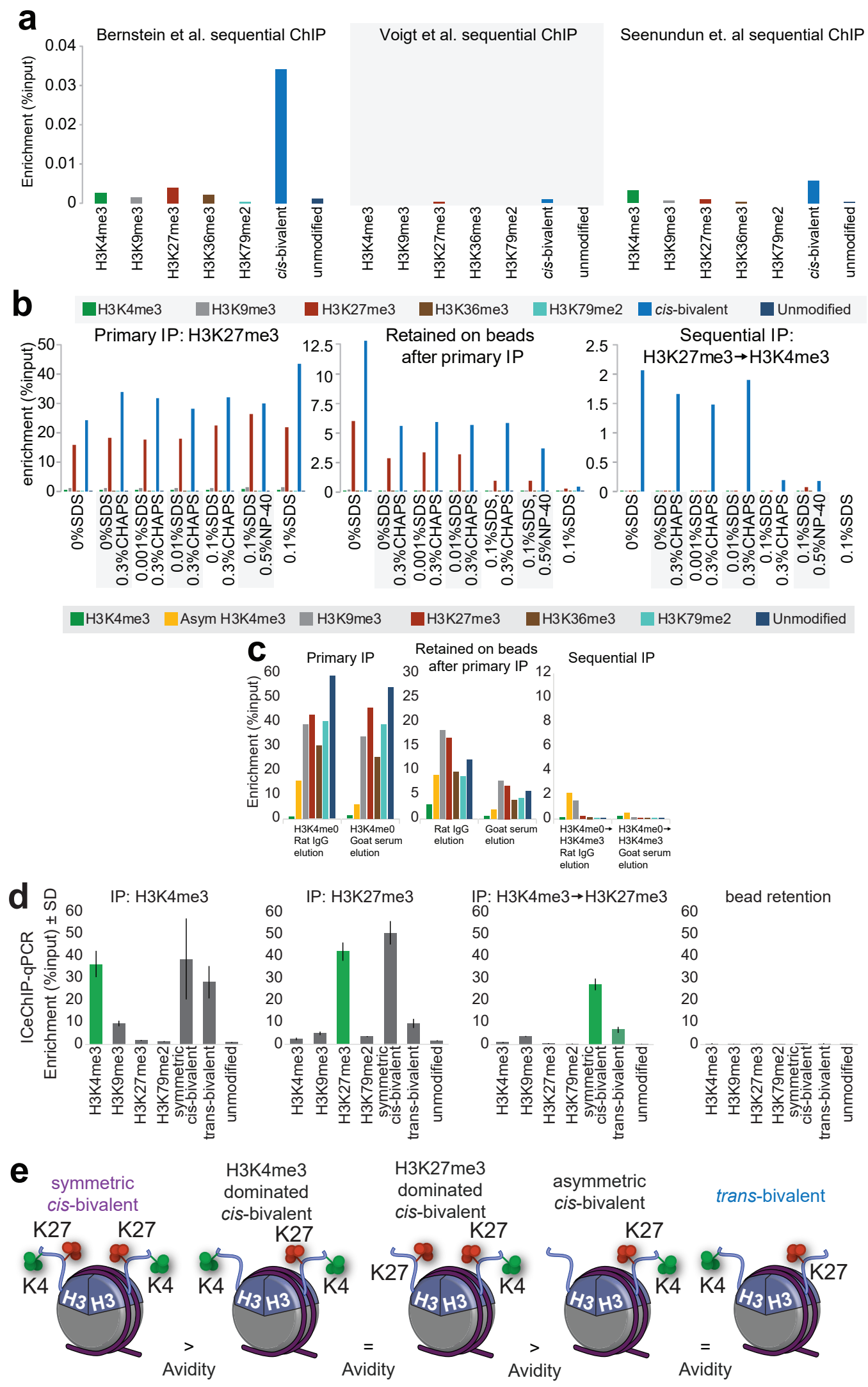

Extended Data Fig. 1 | Evaluation of sequential ChIP methods. (a) Enrichment of on- and off-target nucleosome standards under sequential ChIP protocols developed by Bernstein et al. ${ }^{16}$, Voigt et al..$^{49}$, and Seenundun et al. ${ }^{29}$. (b-c) Enrichment at different sequential ICeChIP steps with (b) chemical denaturant elution and (c) immunoglobulin and serum elution. (d) Enrichment of different nucleosome standards with ICeChIP-qPCR performed against $\mathrm{H} 3 \mathrm{~K} 4 \mathrm{me} 3, \mathrm{H} 3 \mathrm{~K} 27 \mathrm{me} 3$, and bivalency, with beads showing very little retention of chromatin ( $n=3$ technical replicates). Error bars represent standard deviation. (e) Different configurations of bivalency on a single nucleosome. Of these, only trans-bivalency has been identified by mass spectrometry ${ }^{49,81}$. 


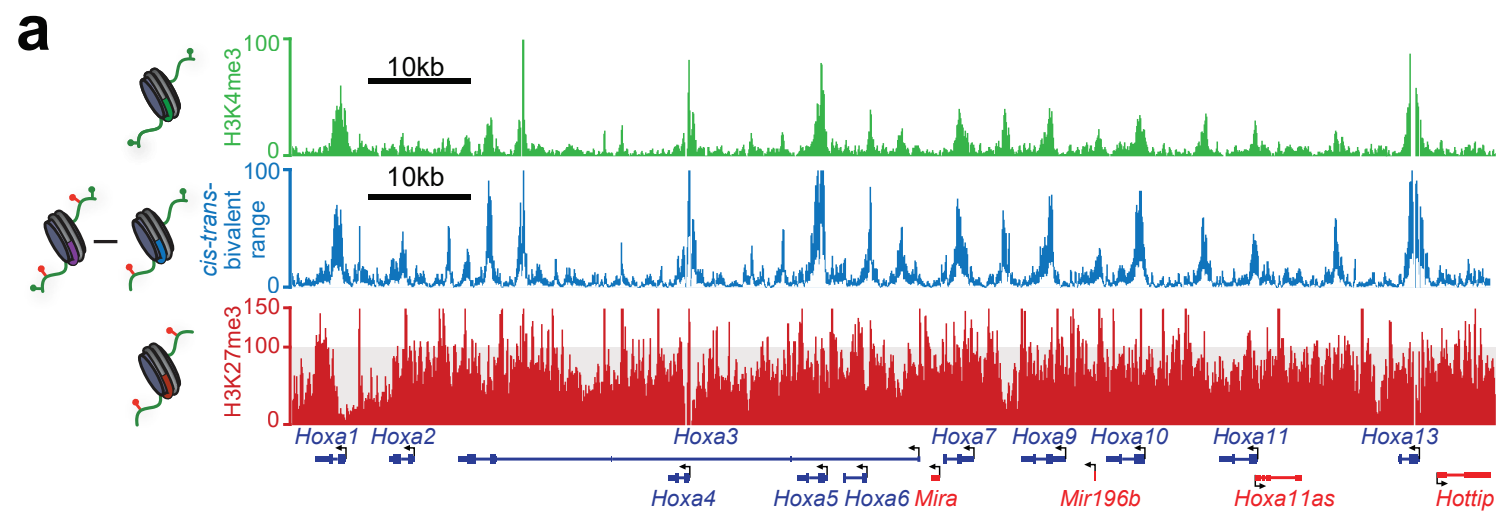

b
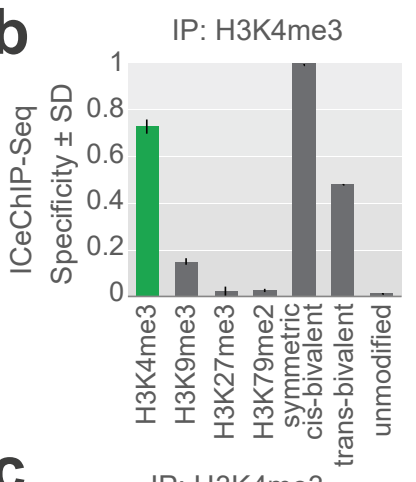

C IP: $\mathrm{H} 3 \mathrm{~K} 4 \mathrm{me3}$

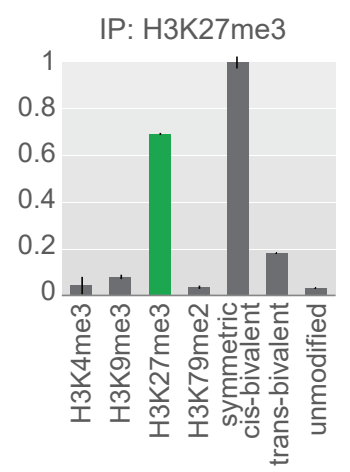

IP: H3K4me3 $\rightarrow$ H3K27me3

IP: H3K9me3
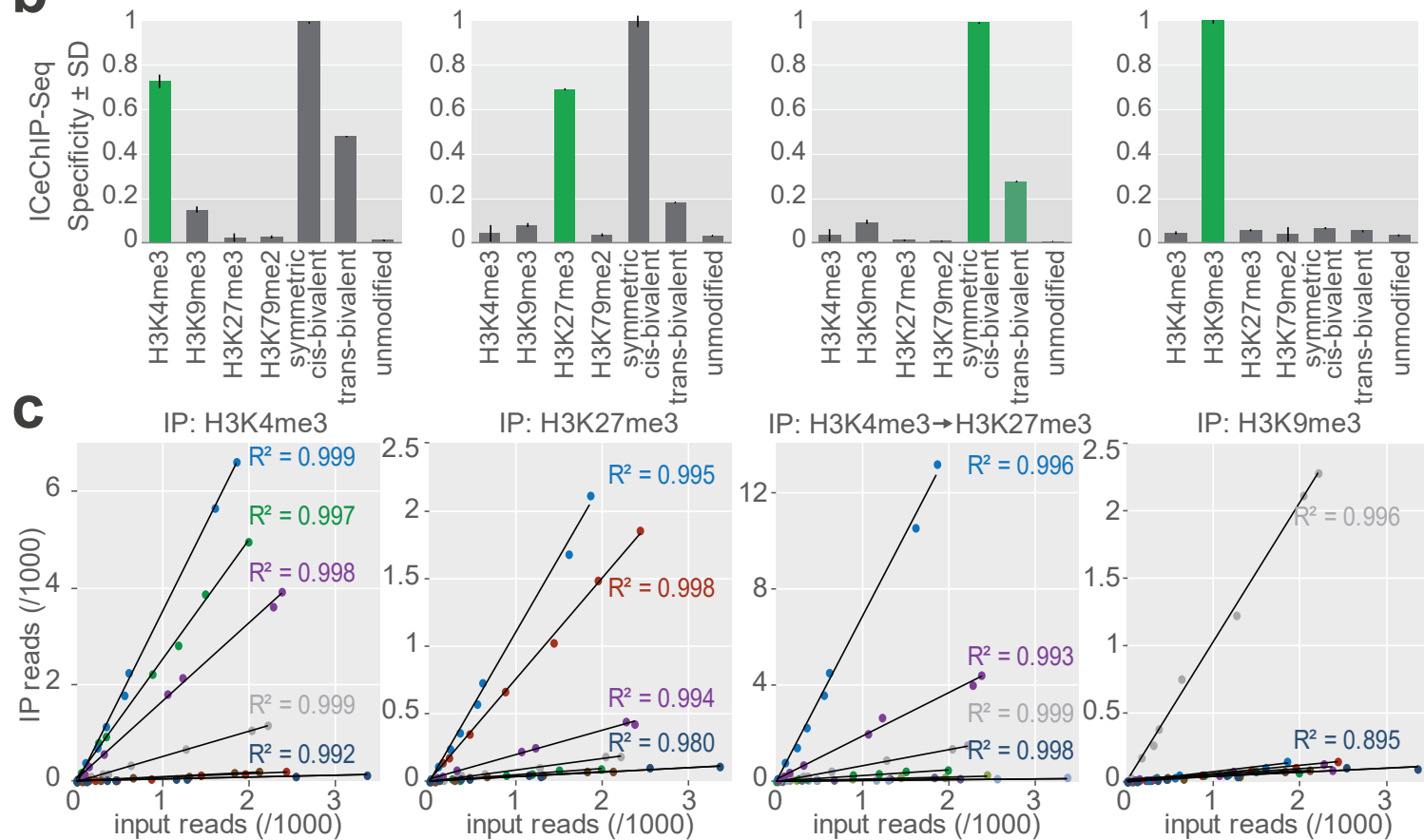

IP: $\mathrm{H} 3 \mathrm{~K} 4 \mathrm{me} 3 \rightarrow \mathrm{H} 3 \mathrm{~K} 27 \mathrm{me} 3$

IP: H3K9me3

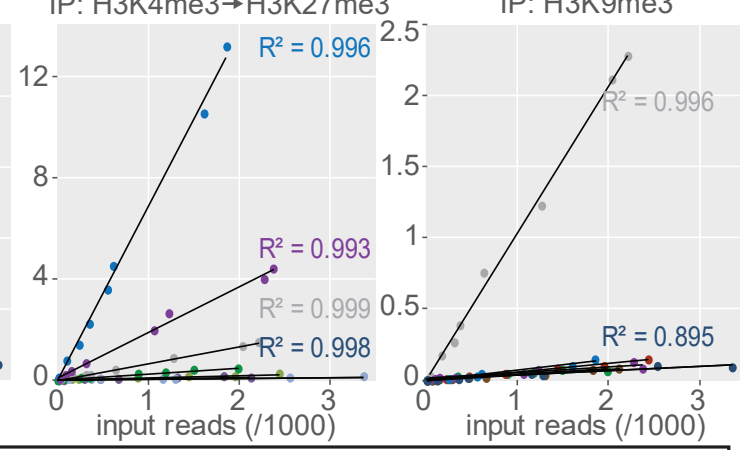

$\bullet$ H3K4me3 •H3K9me3 • H3K27me3 • H3K36me3 •cis-bivalent •trans-bivalent • unmodified
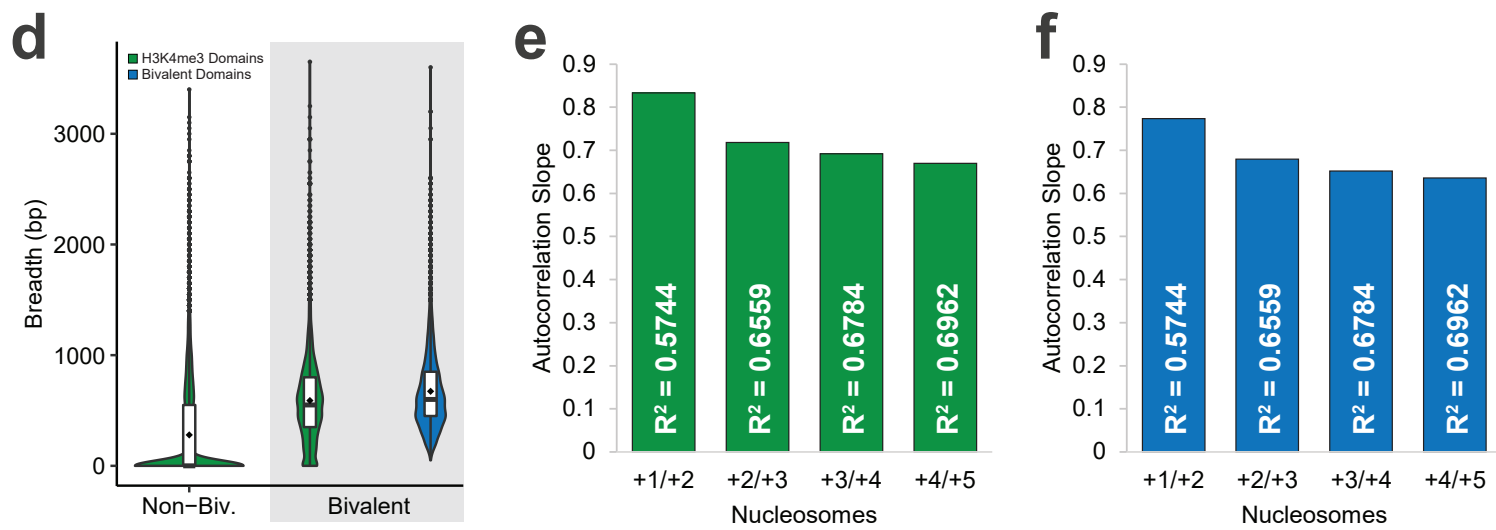

Extended Data Fig. 2 | Evaluation of reICeChIP specificity and standards. (a) Representative genome browser view of $\mathrm{H} 3 \mathrm{~K} 4 \mathrm{me} 3, \mathrm{H} 3 \mathrm{~K} 27 \mathrm{me} 3$, and bivalency, shown as a range of possible values by normalization to trans-bivalent (upper limit) or cis-bivalent (lower limit) nucleosome standards. (b) Relative pulldown of different nucleosome standards in ICeChIP-seq, normalized to the most-enriched standard. (c) Scatterplots of reads from DNA barcodes applied to nucleosome standards in ICeChIP-seq. (d) Violin plots of peak breadth (consecutive segment of 50bp windows overlapping promoter with $>25 \% \mathrm{HMD}$ ) for $\mathrm{H} 3 \mathrm{~K} 4 \mathrm{me} 3$ (green) and bivalency (blue) at non-bivalent and bivalent genes ( $>25 \%$ HMD) in naïve mESCs. (e-f) Autocorrelation of (e) H3K4me3 and (f) bivalency HMDs between nucleosomes in naïve mESCs. Nucleosomes are defined as sequential 200bp windows from the TSS. 
bioRxiv preprint doi: https://doi.org/10.1101/2021.09.09.458948; this version posted September 10, 2021. The copyright holder for this preprint (which was not certified by peer review) is the author/funder, who has granted bioRxiv a license to display the preprint in perpetuity. It is made available under aCC-BY 4.0 International license.

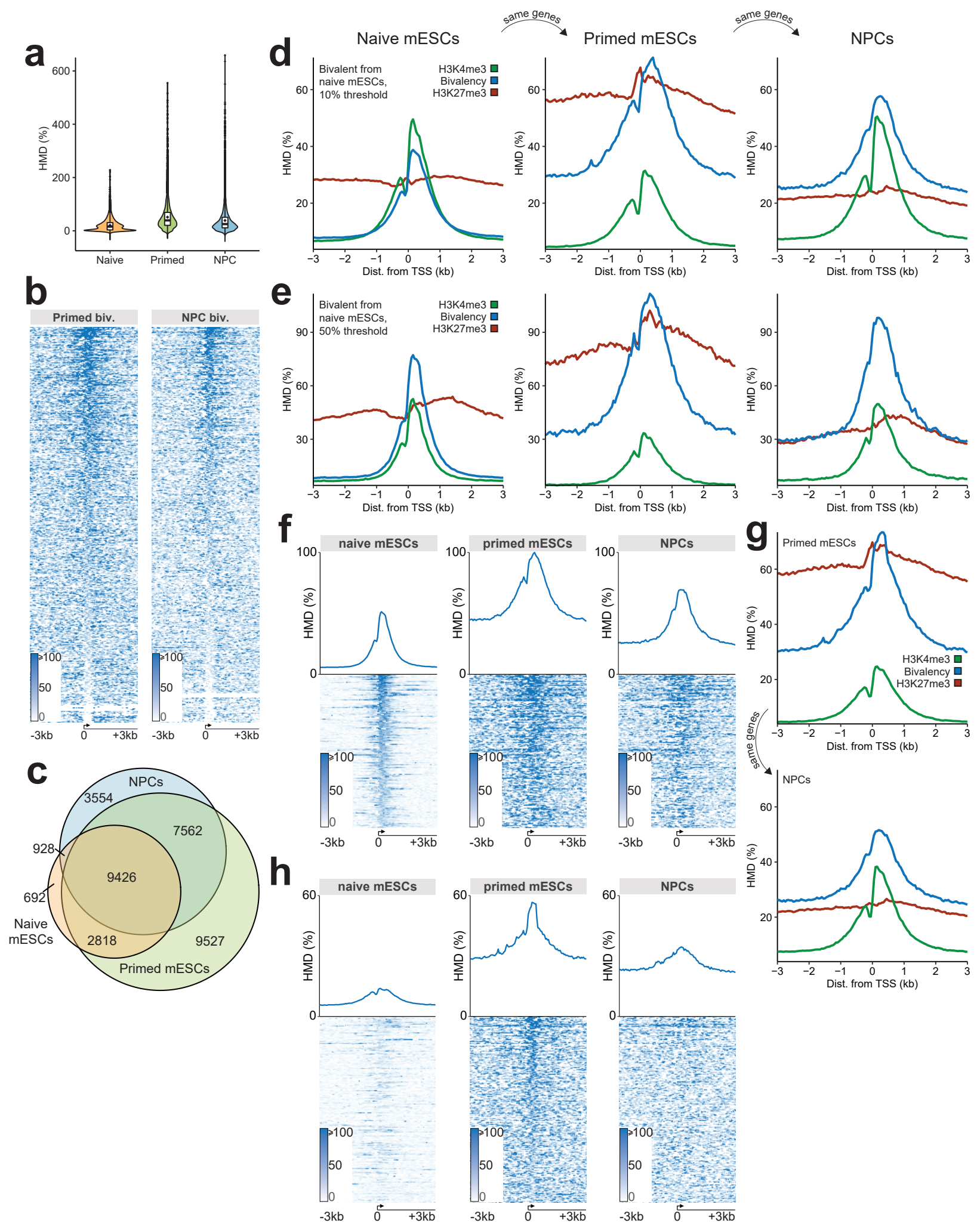

Extended Data Fig. 3 | Tracking bivalent genes through differentiation. (a) Distribution of bivalency HMDs at all Refseq promoters in three cell states. (b) Heatmaps of bivalency at all Refseq promoters in primed mESCs and NPCs. Genes are ordered by bivalency HMD at the promoter. (c) Venn diagram showing overlap of bivalent genes (25\% HMD threshold) in naïve mESCs, primed mESCs, and NPCs. (d-e) Metaprofiles of H3K4me3, H3K27me3, and bivalency for bivalent genes in naïve mESCs with a (d) $10 \%$ or (e) $50 \%$ HMD threshold. (f) Heatmaps and metaprofiles of bivalent genes from naïve mESCs. (g) Metaprofiles of H3K4me3, $\mathrm{H} 3 \mathrm{~K} 27 \mathrm{me}$, and bivalency at genes tracked from primed mESCs to NPCs for bivalent genes in primed mESCs ( $>25 \%$ HMD). (h) Heatmaps and metaprofiles of bivalent genes in primed mESCs that are not bivalent in naïve mESCs. 
bioRxiv preprint doi: https://doi.org/10.1101/2021.09.09.458948; this version posted September 10, 2021. The copyright holder for this preprint (which was not certified by peer review) is the author/funder, who has granted bioRxiv a license to display the preprint in perpetuity. It is made available under aCC-BY 4.0 International license.
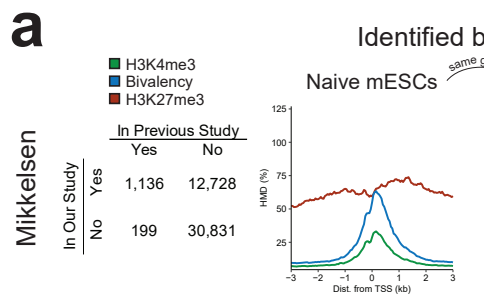

dentified by our study and previous study
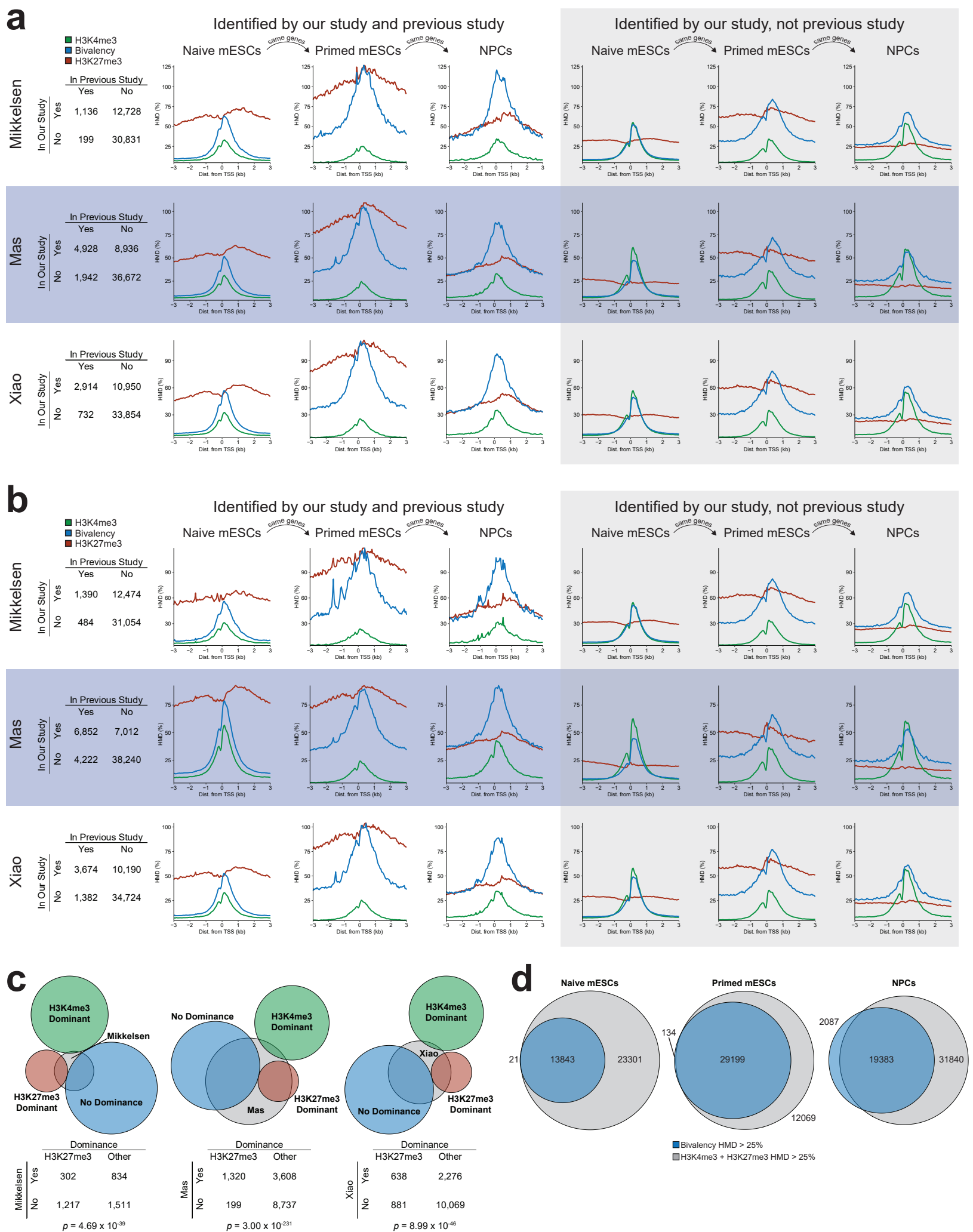

Extended Data Fig. 4 | Comparing our bivalent genes to other studies. (a-b) Contingency tables and metaprofiles for genes that are identified as $>25 \%$ bivalent in our study and by Mikkelsen et al. ${ }^{18}$, Mas et al..$^{35}$, and Xiao et al. ${ }^{58}$, wherein: (a) gene is identified as bivalent in the external study if overlapping H3K4me3 and H3K27me3 peaks overlap the 0 to $+400 \mathrm{bp}$ region of a gene relative to the TSS, or (b) gene is identified as bivalent in the external study if overlapping $\mathrm{H} 3 \mathrm{~K} 4 \mathrm{me} 3$ and $\mathrm{H} 3 \mathrm{~K} 27 \mathrm{me} 3$ peaks overlap the region from $2.5 \mathrm{~kb}$ upstream of the TSS to the end of the gene ${ }^{22}$. (c) Overlap of bivalent genes from external datasets (as defined in part a) with each of our bivalent gene dominance classes in naïve mESCs. Significance computed by two-tailed Fisher hypergeometric test. (d) Overlap of genes with bivalency HMD $>25 \%$ and with H3K4me3 + H3K27me3 HMD $>25 \%$ in all three cell states. 
bioRxiv preprint doi: https://doi.org/10.1101/2021.09.09.458948; this version posted September 10, 2021. The copyright holder for this preprint (which was not certified by peer review) is the author/funder, who has granted bioRxiv a license to display the preprint in perpetuity. It is made available under aCC-BY 4.0 International license.
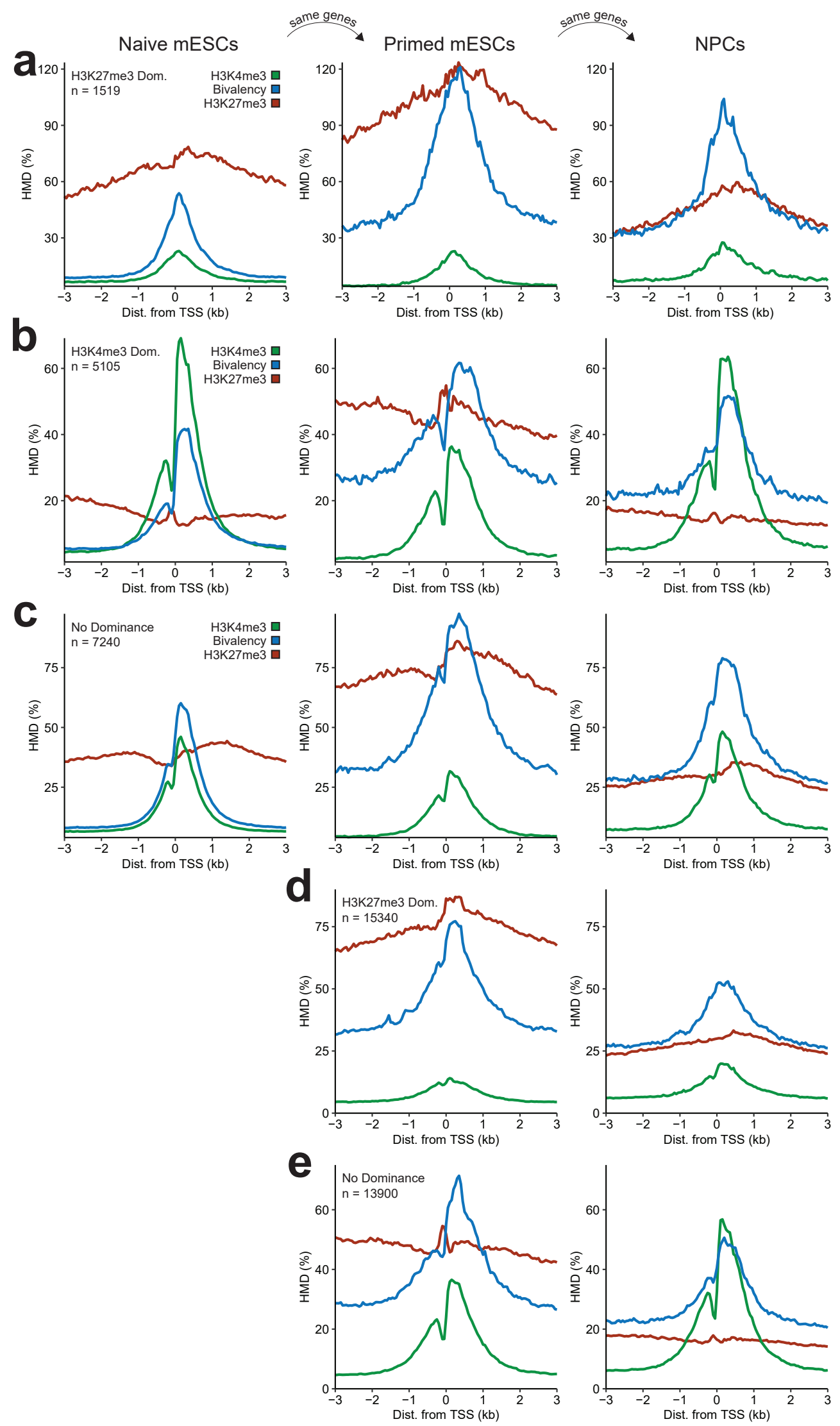

Extended Data Fig. 5 | Bivalency changes across differentiation by modification dominance class. (a-c) Metaprofiles of $\mathrm{H} 3 \mathrm{~K} 4 \mathrm{me} 3, \mathrm{H} 3 \mathrm{~K} 27 \mathrm{me} 3$, and bivalency for bivalent genes ( $>25 \% \mathrm{HMD})$ in naïve mESCs that are (a) H3K27me3 dominant (H3K27me3/H3K4me3 $>e^{l}$ ), (b) H3K4me3 dominant (H3K27me3/H3K4me3< $e^{-1}$ ), or (c) have no dominance in naïve mESCs, tracked through three cell states. (d-e) Metaprofiles of H3K4me3, $\mathrm{H} 3 \mathrm{~K} 27 \mathrm{me} 3$, and bivalency for bivalent genes $(>25 \% \mathrm{HMD})$ in primed $\mathrm{mESCs}$ that are for indicated dominance classes tracked from primed mESCs to NPCs. 

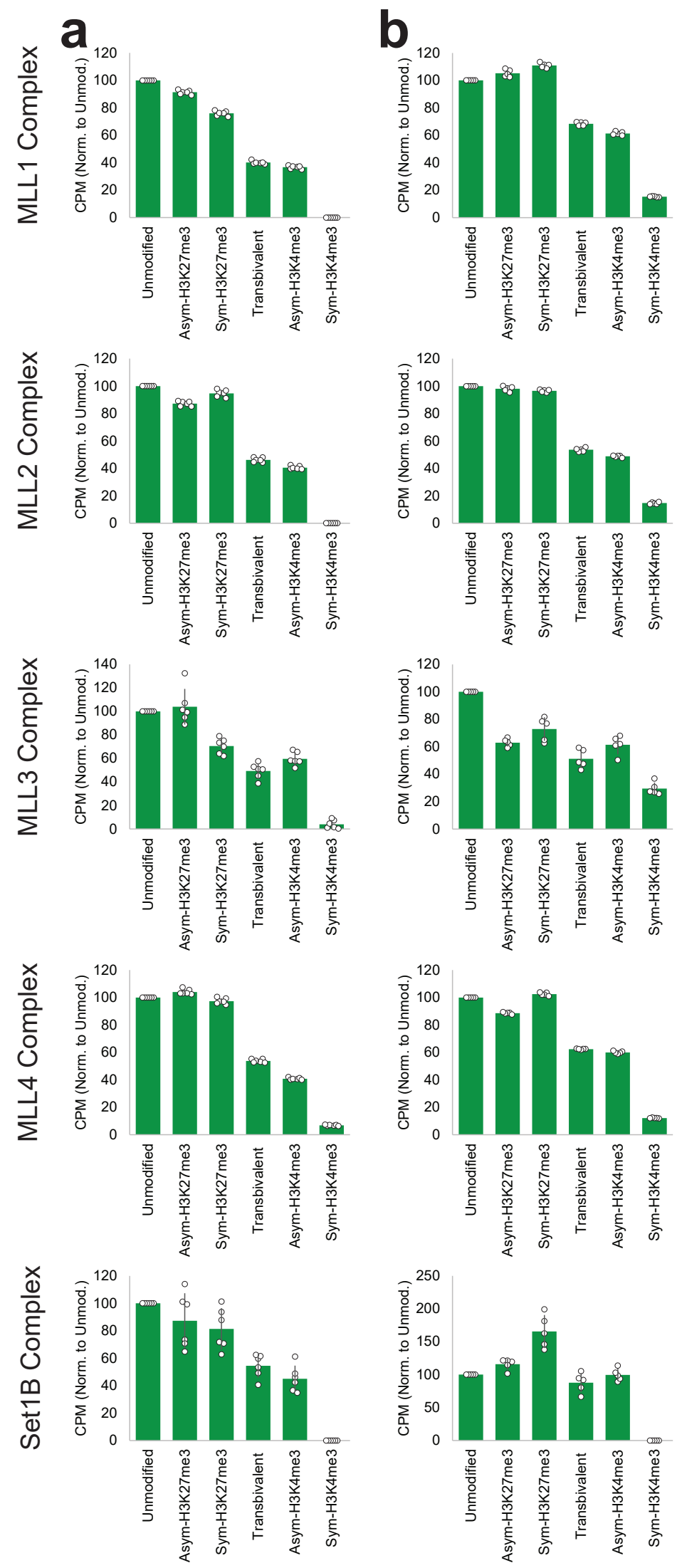

Extended Data Fig. 6 | Methyltransferase assays identifying potential pathways for establishment of bivalency. (a-b) Methyltransferase assays for MLL1, MLL2, MLL3, MLL4, and Set1B core HMTase complexes using (a) $15 \mathrm{ng} / \mathrm{uL}(\mathrm{n}=6)$ and (b) $20 \mathrm{ng} / \mathrm{uL}(\mathrm{n}=5)$ semisynthetic nucleosomes as substrates for methylation. Endpoints were established at $180 \mathrm{~min}$ by kinetic evaluation to be sensitive to difference in activity for this panel. Signal is corrected for background and no nucleosome substrate activity. Error bars represent standard deviation. 
bioRxiv preprint doi: https://doi.org/10.1101/2021.09.09.458948; this version posted September 10, 2021. The copyright holder for this preprint (which was not certified by peer review) is the author/funder, who has granted bioRxiv a license to display the preprint in perpetuity. It is made available under aCC-BY 4.0 International license.
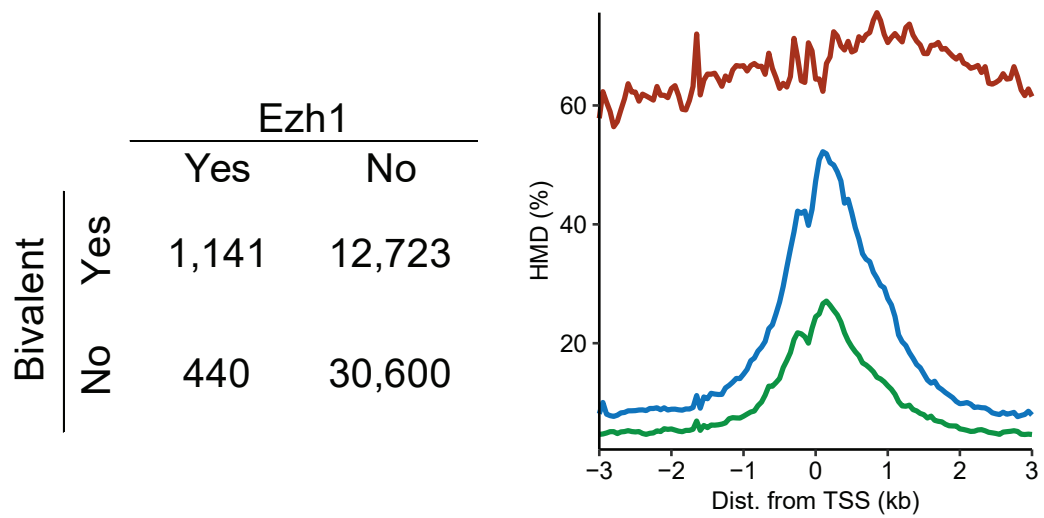

Genes without HMT peak
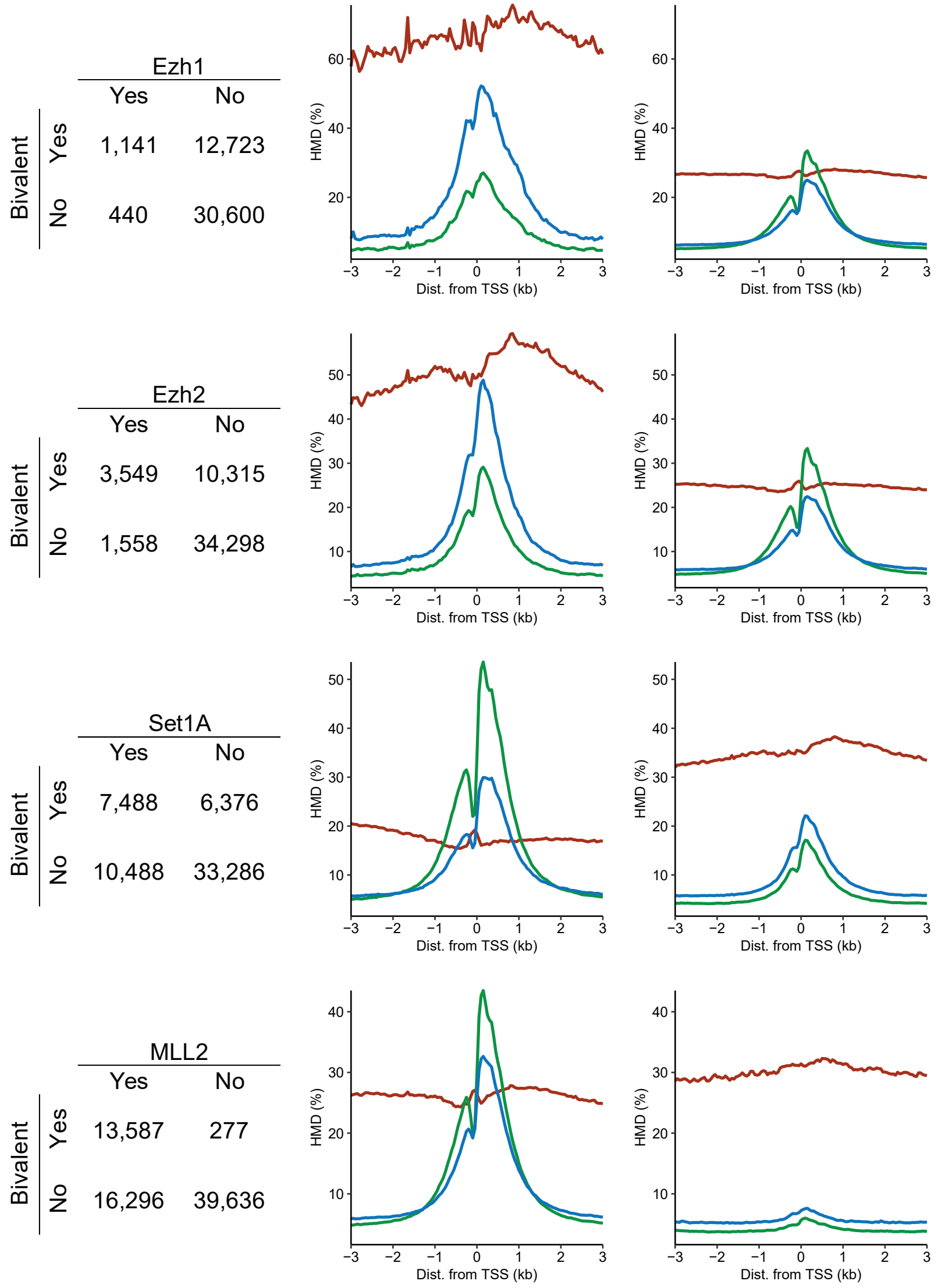

Extended Data Fig. 7 | HMTase peaks and bivalency. Contingency tables and metagene profiles in naïve mESCs for genes with and without overlapping HMT peaks. Ezh1 and Ezh2 peaks were identified as Suz12 peaks lost upon Ezh1 or Ezh2 knockout ${ }^{82}$. Set1A peaks were identified by ChIP against Set1A ${ }^{62}$. M112 peaks were identified by ChIP against $\mathrm{M}_{112}{ }^{45}$. 
bioRxiv preprint doi: https://doi.org/10.1101/2021.09.09.458948; this version posted September 10, 2021. The copyright holder for this preprint (which was not certified by peer review) is the author/funder, who has granted bioRxiv a license to display the preprint in perpetuity. It is made available under aCC-BY 4.0 International license.
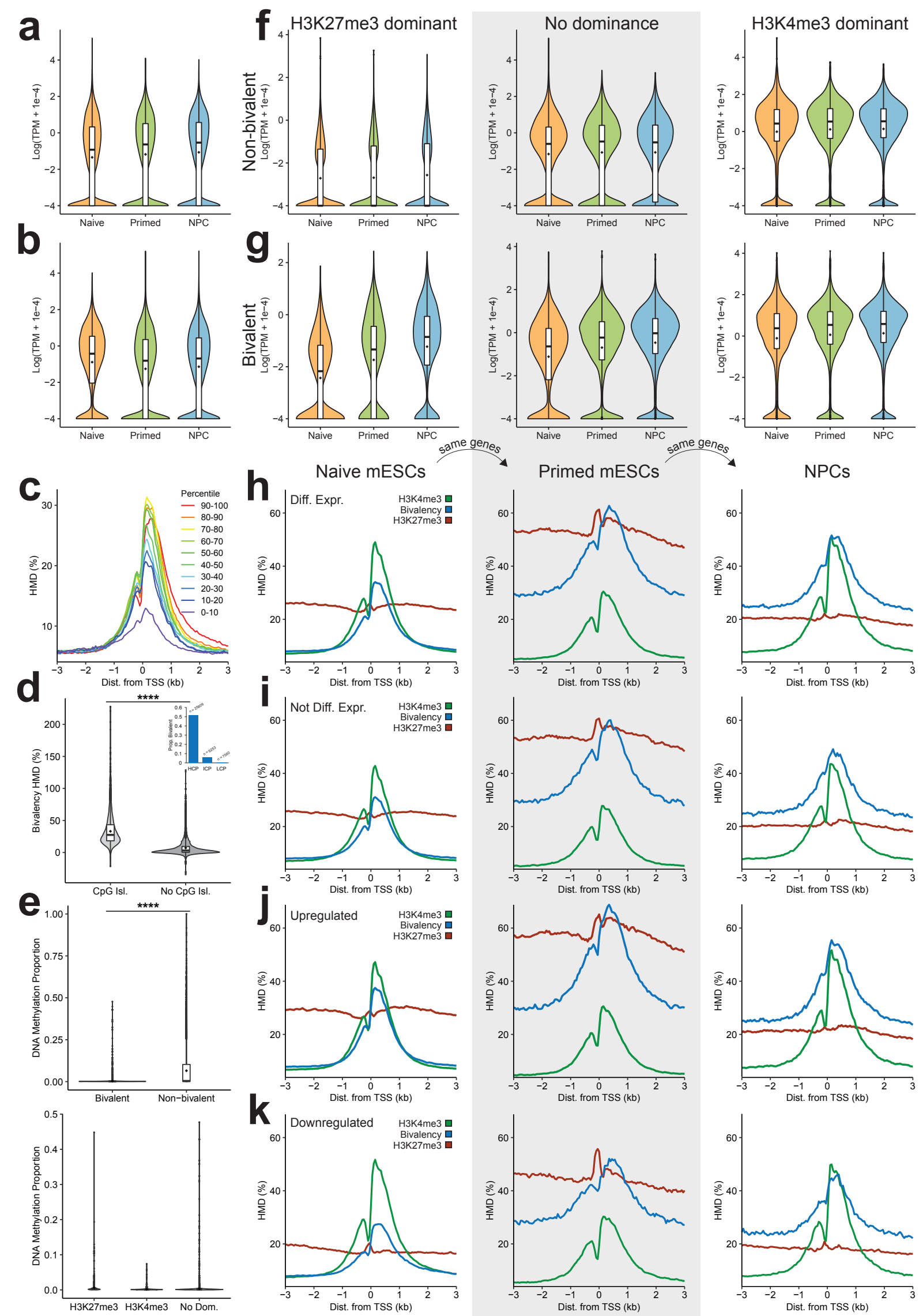

Extended Data Fig. 8 | Bivalency and differential gene expression. (a-b) Violin plots of gene expression for (a) all genes and (b) bivalent (>25\% HMD) genes in each cell state. (c) Bivalency metaprofiles in naïve mESCs at promoters binned by gene expression decile. (d) Violin plots of bivalency HMD in naïve mESCs at promoters with and without $\mathrm{CpG}$ islands. Inset shows proportion of genes that are bivalent in sets of genes classified by $\mathrm{CpG}$ content: high-CpG promoters (HCP), intermediate-CpG promoters (ICP), and low-CpG promoters 
(LCP), defined as previously described by Mikkelsen et al. ${ }^{18}$. Total number of genes in each class is provided as n. (e) Violin plots of DNA methylation at bivalent and non-bivalent genes (top), broken by dominance class for bivalent genes (bottom). (f-g) Violin plots of gene expression in (f) non-bivalent ( $<25 \% \mathrm{HMD})$ and (g) bivalent $\left(>25 \%\right.$ HMD) genes from naïve mESCs that are H3K27me3 dominant (H3K27me3/H3K4me3 > $e^{l}$; left), have no clear dominance (centre), or are H3K4me3 dominant (H3K27me3/H3K4me3 < $e^{-1}$; right). (h-k) Metaprofiles of H3K4me3, H3K27me3, and bivalency at genes tracked from naïve mESCs to primed mESCs to NPCs for (h) DEGs, (i) non-DEGs, (j) genes upregulated from naïve mESCs to NPCs, and (k) genes downregulated from naïve mESCs to NPCs. $* * * * p<10^{-16}$ (Welch's two-tailed t-test). 
bioRxiv preprint doi: https://doi.org/10.1101/2021.09.09.458948; this version posted September 10, 2021. The copyright holder for this preprint (which was not certified by peer review) is the author/funder, who has granted bioRxiv a license to display the preprint in perpetuity. It is made available under aCC-BY 4.0 International license.

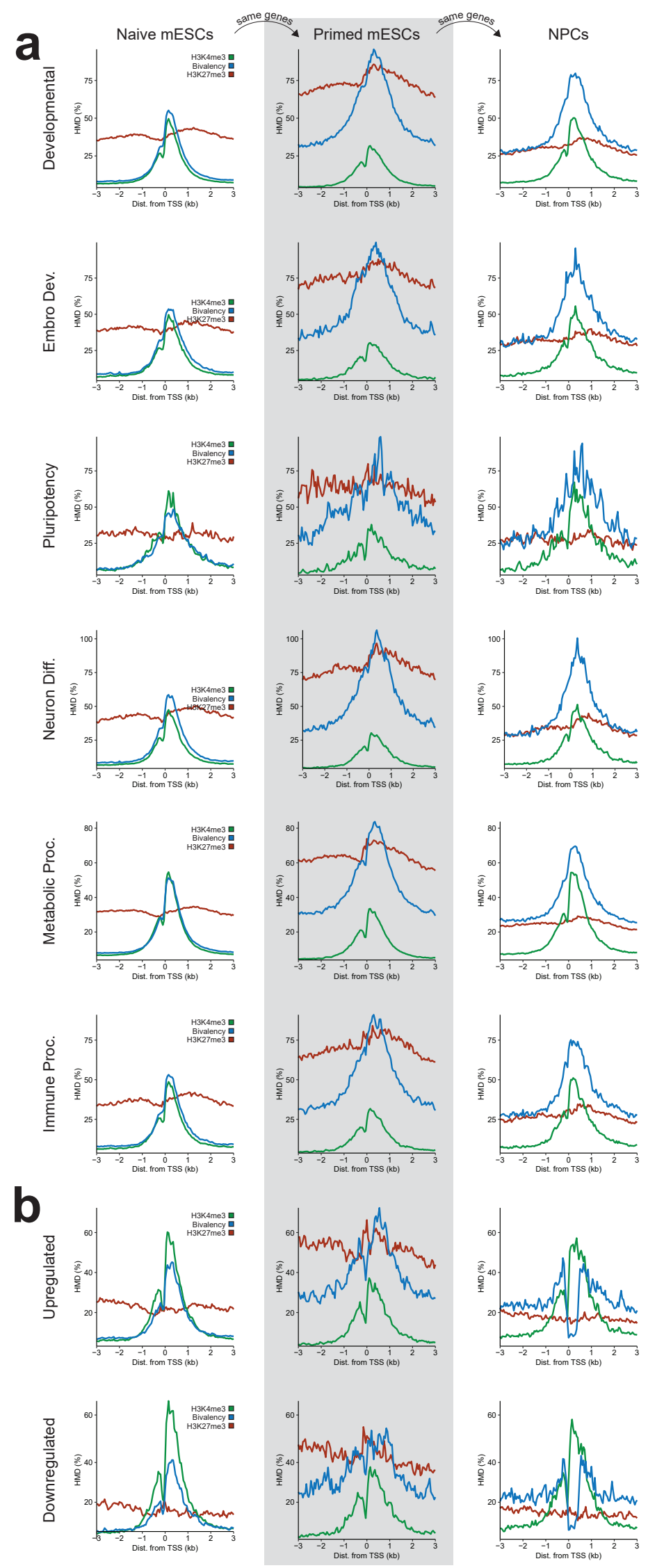

Extended Data Fig. 9 | Bivalency at different classes of genes. (a) Metaprofiles of H3K4me3, H3K27me3, and bivalency at genes tracked from naïve mESCs to primed mESCs to NPCs for bivalent genes of indicated gene ontology terms. (b) Metaprofiles of H3K4me3, H3K27me3, and bivalency at genes tracked across differentiation for genes that lose bivalency at the promoters ( 0 to $+400 \mathrm{bp}$ relative to TSS) from naïve $\mathrm{mESCs}(>25 \%$ HMD) to NPCs (<10\% HMD) and are upregulated (top) or downregulated (bottom) over differentiation. 

available under aCC-BY 4.0 International license.
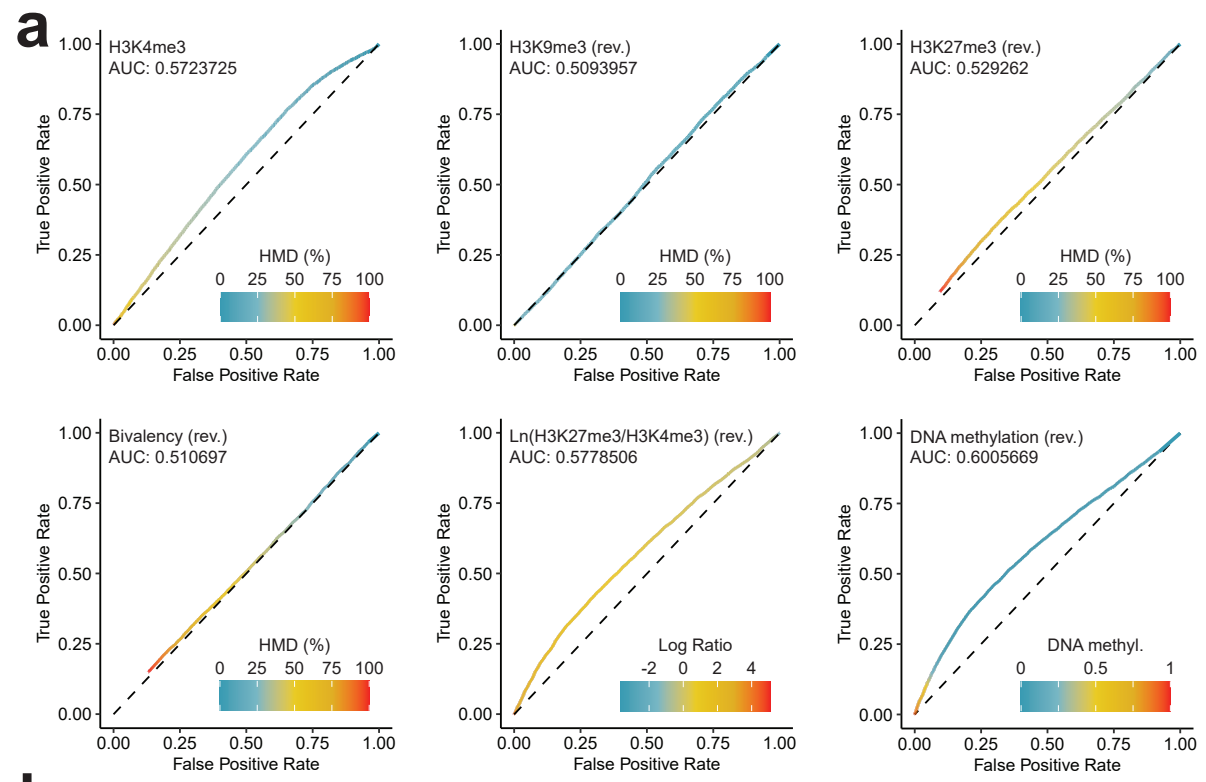

b
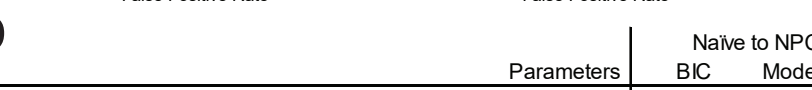

\begin{tabular}{c|cc} 
NPC & \multicolumn{2}{|c}{ Primed to NPC } \\
Model Rank & BIC & Model Rank \\
\hline 1 & 28572.21 & 1 \\
2 & 28690.06 & 4 \\
3 & 28698.28 & 5 \\
4 & 28575.32 & 2 \\
5 & 28743.02 & 6 \\
6 & 28749.58 & 7 \\
7 & 28812.13 & 8 \\
8 & 28642.26 & 3 \\
9 & 29061.58 & 11 \\
10 & 29060.79 & 10 \\
11 & 29019.73 & 9 \\
12 & 29070.02 & 12
\end{tabular}
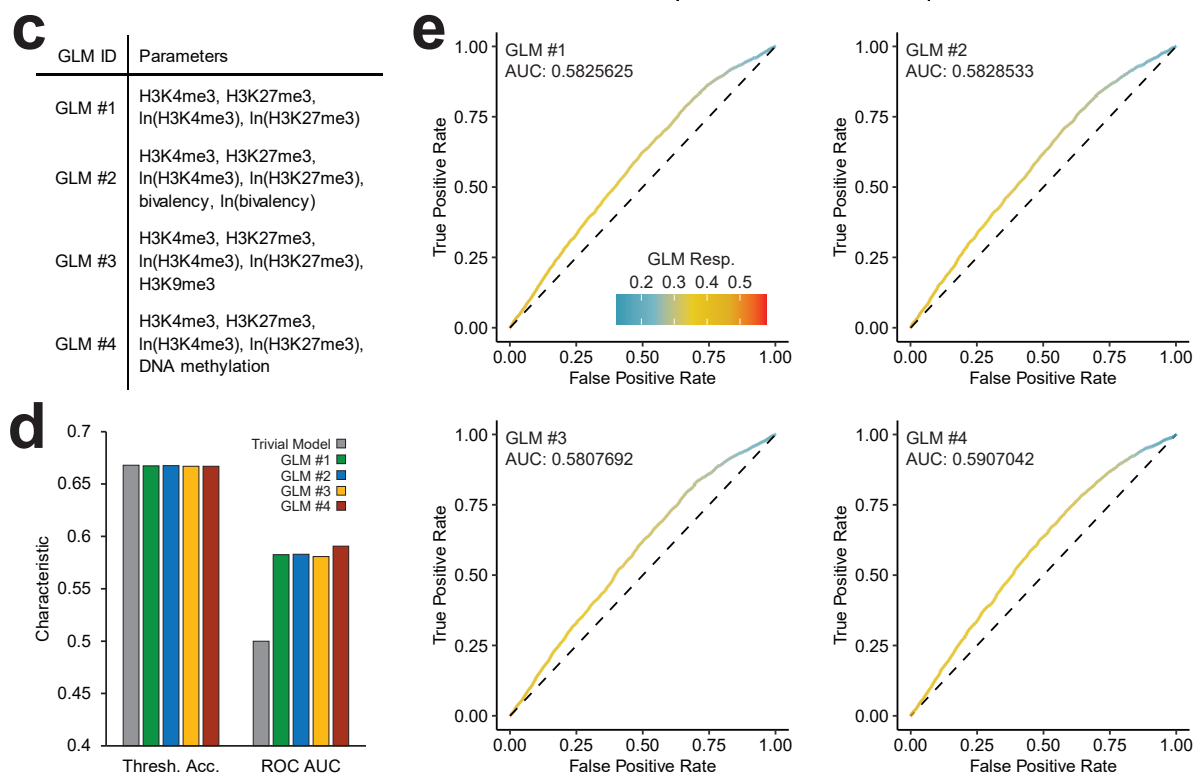

Extended Data Fig. 10 | Modelling the additional information content provided by bivalency over H3K4me3 and H3K27me3 alone. (a) ROC curves for identifying DEGs from primed mESCs to NPCs by H3K4me3, H3K9me3, H3K27me3, bivalency, $\ln (\mathrm{H} 3 \mathrm{~K} 27 \mathrm{me} 3 / \mathrm{H} 3 \mathrm{~K} 4 \mathrm{me} 3)$, or DNA methylation in primed mESCs. For each point, parameter value threshold used to compute true positive rate (TPR) and false positive rate (FPR) is indicated by the colour. Traits with thresholds identifying non-DEGs rather than DEGs are marked with "rev." (b) Bayes Information Criterion (BIC) for logistic models identifying DEGs from naïve mESCs or primed mESCs to NPCs with different parameters. (c) Legend for generalized linear models (GLMs). (d) Accuracy of trivial model and GLMs by threshold accuracy (gene identified as DEG if logistic regression $>0.5$; left) and by ROC area under curve (right). (e) ROC curves for identifying DEGs from primed mESCs to NPCs by different GLMs. For each point, logistic regression threshold value used to compute TPR and FPR is indicated by the colour. 